\title{
Climatology of northern polar latitude MLT dynamics: mean winds and tides
}

\author{
G. Kishore Kumar ${ }^{1, *}$ and W. K. Hocking ${ }^{1}$ \\ ${ }^{1}$ Department of Physics and Astronomy, University of Western Ontario, London, Canada \\ *now at: Leibniz-Institute of Atmospheric Physics, Germany
}

Received: 27 January 2010 - Revised: 10 September 2010 - Accepted: 14 September 2010 - Published: 7 October 2010

\begin{abstract}
Mean winds and tides in the northern polar Mesosphere and Lower Thermosphere (MLT) have been studied using meteor radars located at Resolute Bay $\left(75^{\circ} \mathrm{N}, 95^{\circ} \mathrm{W}\right)$ and Yellowknife $\left(62.5^{\circ} \mathrm{N}, 114.3^{\circ} \mathrm{W}\right)$. The measurements for Resolute Bay span almost 12 years from July 1997 to February 2009 and the Yellowknife data cover 7 years from June 2002 to October 2008. The analysis reveals similar wind flow over both sites with a difference in magnitude. The summer zonal flow is westward at lower heights, eastward at upper heights and the winter zonal flow is eastward at all heights. The winter meridional flow is poleward and sometimes weakly equatorward, while non winter months show equatorward flow, with a strong equatorward jet during mid-summer months. The zonal and meridional winds show strong interannual variation with a dominant annual variation as well as significant latitudinal variation. Year to year variability in both zonal and meridional winds exists, with a possible solar cycle dependence. The diurnal, semidiurnal and terdiurnal tides also show large interannual variability and latitudinal variation. The diurnal amplitudes are dominated by an annual variation. The climatological monthly mean winds are compared with CIRA 86, GEWM and HWM07 and the climatological monthly mean amplitudes and phases of diurnal and semidiurnal tides are compared with GSWM00 predictions. The GEWM shows better agreement with observations than the CIRA 86 and HWM07. The GSWM00 model predictions need to be modified above $90 \mathrm{~km}$. The agreements and disagreements between observations and models are discussed.
\end{abstract}

Keywords. Meteorology and atmospheric dynamics (Middle atmosphere dynamics)

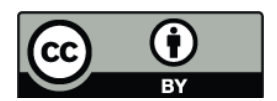

Correspondence to: G. Kishore Kumar (kishoreg@ rocketmail.com)

\section{Introduction}

The mesosphere and lower thermosphere (MLT) is a complex transitional region and is dominated by tides, gravity waves and planetary waves, which have important impact on the dynamics of the MLT region. For example, the winter polar mesopause is hotter than the summer polar mesopause, and this phenomenon is well explained by considering the gravity-wave momentum deposition in addition to the general energy budget. Understanding this region is also important for the lower atmosphere. For example, tides and gravity waves in the MLT region are diagnostic of the dynamics and photochemistry of the troposphere and stratosphere. The polar MLT region is the least explored region, comparatively, of the global MLT region, due to difficulties in observations over these latitudes.

Medium Frequency and Meteor radars are crucial ground based tools for understanding the MLT region with high vertical and temporal resolution. Here we used the meteor method. The Meteor radar technique, when implemented properly, can provide both wind and temperature information. It is based on the ionized column (meteor trail) created by meteor ablations. These ionized columns can strongly backscatter radar pulses in a direction at right angles to the long axis of the ionized column. By measuring the Doppler shift resulting from the motion of the meteor trail, a pulsed Doppler radar can be used to profile the neutral winds in the meteor region. Study of the MLT region using meteor technique began in the 1950s without height information (e.g., Manning et al., 1950; Robertson et al., 1953). Later developments in the meteor radar technique provided further information about the MLT region like winds, tides, gravity waves and planetary waves with specific height resolution. Meteor radars have become valuable tools for probing MLT dynamics, especially in the 1990s and beyond. 

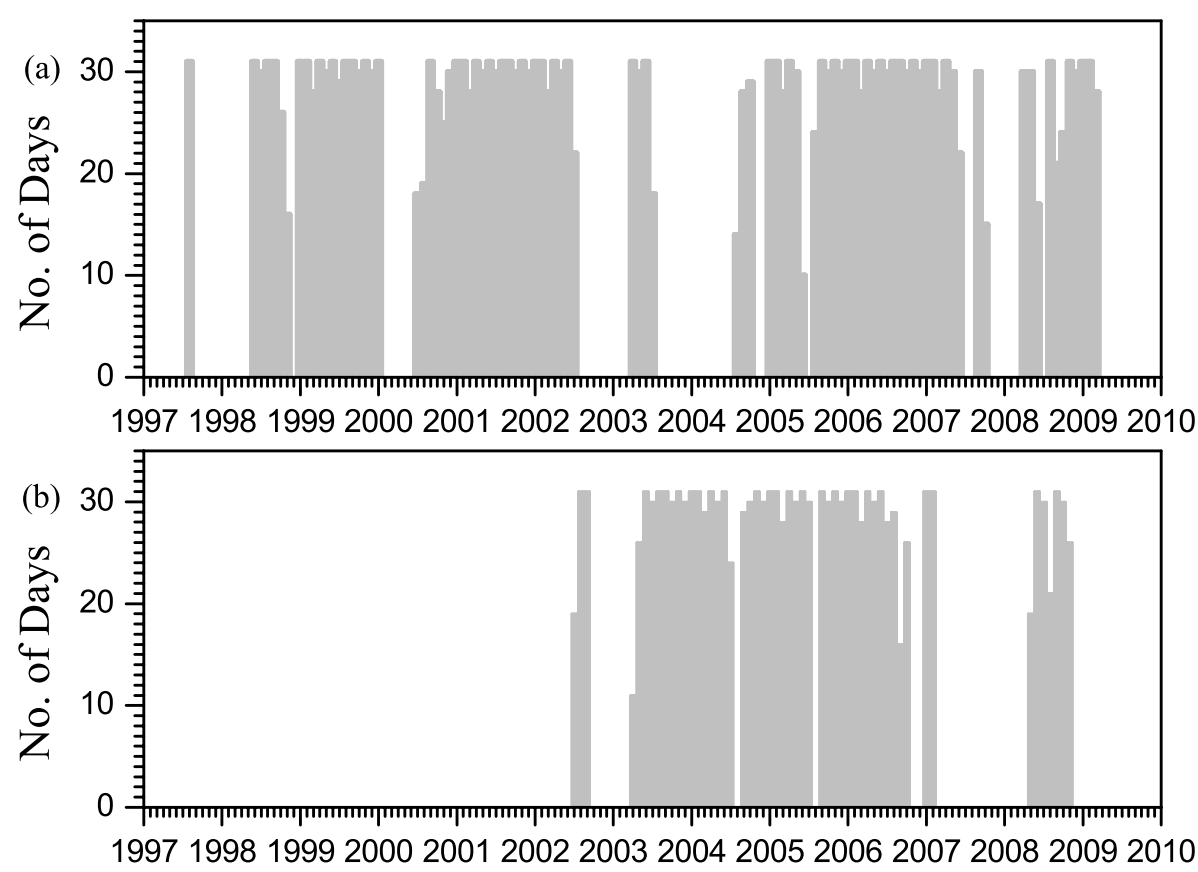

Month

Fig. 1. Number of days are available from each month (a) for Resolute Bay (RB) (from July 1997-February 2009), (b) for Yellowknife (YK) (from June 2002-October 2008).

Over arctic latitudes, studies of mean wind and tides have been carried out using limited data of lengths of typically less than 1-2 years (e.g., Hocking, 2001; Mitchell et al., 2002; Manson et al., 2009) and only a few observations deal with long term observations (Portnyagin et al., 2004; Day and Mitchell et al., 2010). But there are no long term observations such as those made over mid- and low-latitudes (Nakamura et al., 1996; Kishore Kumar et al., 2008, and references therein). This is mainly due to the difficulty of observations over polar latitudes. Satellites have also provided a wealth of information about the low and mid latitude MLT region, whereas their coverage of polar latitudes is less complete. Manson et al. (1999) studied the interannual variability of tides in different latitudes from $2^{\circ} \mathrm{N}$ to $70^{\circ} \mathrm{N}$ using MF radar observations. In addition to the ground based observations, satellite observations like HRDI and WINDII aboard UARS, and TIDI aboard TIMED (Burrage et al., 1995; Oberheide et al., 2006) have also provided good information about the tidal characteristics on a global basis. However, the tidal interannual variability is unclear in the Polar Regions.

In this paper, we report on the climatological mean wind fields and tides in the northern polar MLT region using two radars located at Resolute Bay $\left(75^{\circ} \mathrm{N}, 95^{\circ} \mathrm{W}\right)$ and Yellowknife $\left(62.5^{\circ} \mathrm{N}, 114.3^{\circ} \mathrm{W}\right)$. The system descriptions of the radars and their characteristics are mentioned in detail in Sect. 2, which also deals with the database and data analysis used for the present study. In Sects. 3.1 and 3.2 we discuss the mean winds and their interannual variability observed over Resolute Bay and Yellowknife. Comparisons made with models like HWM07, GEWM and CIRA86 are mentioned in Sect. 3.3. Sections 3.4 and 3.5 deal with the mean tidal information and their interannual variability, and the comparisons between observations and the GSWM model predictions are presented in Sect. 3.6. Finally, the summary and conclusions made from the present study are considered in Sect. 4.

\section{Data base and analysis}

In the present study, we concentrate mainly on the mean winds and tides over the northern polar MLT region (82$94 \mathrm{~km}$ ) using long term observations available at Resolute Bay $\left(75^{\circ} \mathrm{N}, 95^{\circ} \mathrm{W}\right)$ and Yellowknife $\left(62.5^{\circ} \mathrm{N}, 114.3^{\circ} \mathrm{W}\right)$. The data available from each radar site are illustrated in Fig. 1. We have used 93 months of observations over Resolute Bay (here-after RB) for the time span from July 1997 to February 2009, and 59 months of observations over Yellowknife (here-after YK) for the time span from June 2002 to October 2008.

The RB VHF radar is located at the Early Polar Cap Observatory and this radar was operated in interferometeric mode at a frequency of $51.5 \mathrm{MHz}$. The full system description can be found in Hocking (2001). It is important to mention that the RB radar has been upgraded in June 2000 by installing four separate receivers in place of a multiplexer so that the meteor count after the upgrade was improved by 
4-5 times (before the upgrade the meteor count was 300800 per day whereas after June 2000 it was around 1500 per day and on some occasions reached around 2500 (Hocking, 2001)). Although a count rate of $300-800$ seems to be small, studies made with similar radars elsewhere showed these counts are sufficient to retrieve monthly mean winds and tides (Hocking and Thayaparan, 1997). The Yellowknife radar is a SKiYMET Radar (Hocking et al., 2001) and operates at $35.65 \mathrm{MHz}$. The main specifications of the radars used in the present study are listed in Table 1.

To represent clear climatological values, we followed some specific criteria while choosing the data. Accordingly we considered only those months in which more than 10 days of data were available with more than $20 \mathrm{~h}$ observations per day. Due to reduced observational time per day, we ignore 9 months of YK data, 3 months in 2006 and 6 months in 2007, even though we have more than 10 days observations during those months. In this way, the quality of the data set is highly improved.

The wind estimation is based on a least square fit analysis. The wind analysis is performed using software developed by Hocking et al. (2001), and provides two hourly zonal and meridional winds in six height range bins viz., 82, 85, 88, 91,94 and $98 \mathrm{~km}$. Due to a reduced number of meteors, and ionospheric contamination at the upper height, we have confined our analysis to $82-94 \mathrm{~km}$ for the present study. The winds refer to a height bin of about $\pm 2 \mathrm{~km}$ around the representative height. Two hourly winds have been averaged to produce daily averages. Those daily mean winds have been used to calculate the monthly mean winds, which are used to study the long term variations of winds and also to generate the climatological monthly means.

In regard to the tidal analysis, this can be carried out by two methods. In one method the tidal amplitudes and phases can be calculated on a daily basis and those values may be averaged for a month to obtain a monthly mean. The second method is a composite analysis. In this method, the residual meteor velocities are binned accordingly to the time of day in one hour bins (composite day), and tidal fits are performed to the composite day. The composite tidal analysis reduces the errors in estimation of tidal amplitude and phase, especially if there are any ambiguous wind values. We therefore concentrated on the composite tidal analysis. Tidal amplitudes and phases for different tidal modes (diurnal, semidiurnal and terdiurnal) are retrieved by applying a simple linear least square fit with mean, 24, 12 and $8 \mathrm{~h}$ harmonic components. The data points were weighted in the fitting process according to the number of individual measurements comprising each hourly mean. The monthly composite values of tidal amplitudes and phases are used to study the long term variations of the tides and to generate the climatological mean values of tidal amplitudes and phases.

The climatological monthly mean winds are compared with different empirical models like HWM07 (Drob et al., 2008) which is the extended version of HWM93, the Global
Table 1. Basic parameters of the Resolute Bay VHF radar and Yellowknife SKiYMET radar.

\begin{tabular}{lll}
\hline Parameter & Resolute Bay & Yellowknife \\
\hline Frequency & $51.5 \mathrm{MHz}$ & $35.65 \mathrm{MHz}$ \\
Peak Power & $12 \mathrm{~kW}$ & $6 \mathrm{~kW}$ \\
Pulse Width & $2 \mathrm{~km}$ & $2 \mathrm{~km}$ \\
Pulse Repetition Frequency & $750 \mathrm{~Hz}$ & $2144 \mathrm{~Hz}$ \\
TX Antenna & 4 Yagis & One $3 \mathrm{Element}$ \\
& & Yagi \\
RX Antenna & Four 3 Element & Five 3 Element \\
& Yagis & Yagis \\
Height Resolution & $\sim 3 \mathrm{~km}$ & $\sim 3 \mathrm{~km}$ \\
\hline
\end{tabular}

Empirical Wind Model (GEWM) for the MLT region developed by Portnyagin et al. (2004), and the COSPAR International Reference Atmosphere-1986 (CIRA-86). The important details of each model are mentioned in the next section while comparing the models with observations. The climatological monthly means of the diurnal and semidiurnal tidal amplitudes and phases are compared with Global-Scale Wave Model (GSWM-00) predictions (Hagan et al., 1995, 1997, 1999).

\section{Results and discussion}

\subsection{Mean winds - composite monthly mean variation}

First we intend to describe the general characteristics of MLT winds over the observational sites. For this purpose the climatological monthly mean winds for zonal and meridional components over RB and YK are illustrated in Fig. 2a. In the figure, the zero wind line is marked with a heavy dashed contour. Here the positive zonal (meridional) wind values represent the eastward (northward or poleward) wind, while the negative zonal (meridional) wind values represent the westward (southward or equatorward) wind flow.

During summer months, at the lower heights, the zonal wind is westward with peak values occurring around $82 \mathrm{~km}$ (or possibly below $82 \mathrm{~km}$ ) over both sites. A difference in magnitude at the sites is apparent which may be due to the latitudinal variation of the summer mesospheric westward jet. In the upper height region, the zonal wind is eastward with peak amplitude $\sim 10 \mathrm{~m} \mathrm{~s}^{-1}$ for RB and $>25 \mathrm{~m} \mathrm{~s}^{-1}$ for YK. During summer months the eastward wind extends to the lower heights, indicating that the shear zone is descending in height with the progression of summer. The observed summer wind flow is similar to earlier results derived with other high latitude observations. For example, observations made by Manson and Meek (1991) over Troms $\varnothing\left(70^{\circ} \mathrm{N}\right)$ using MF radar observations for the period mid 1987-1989 

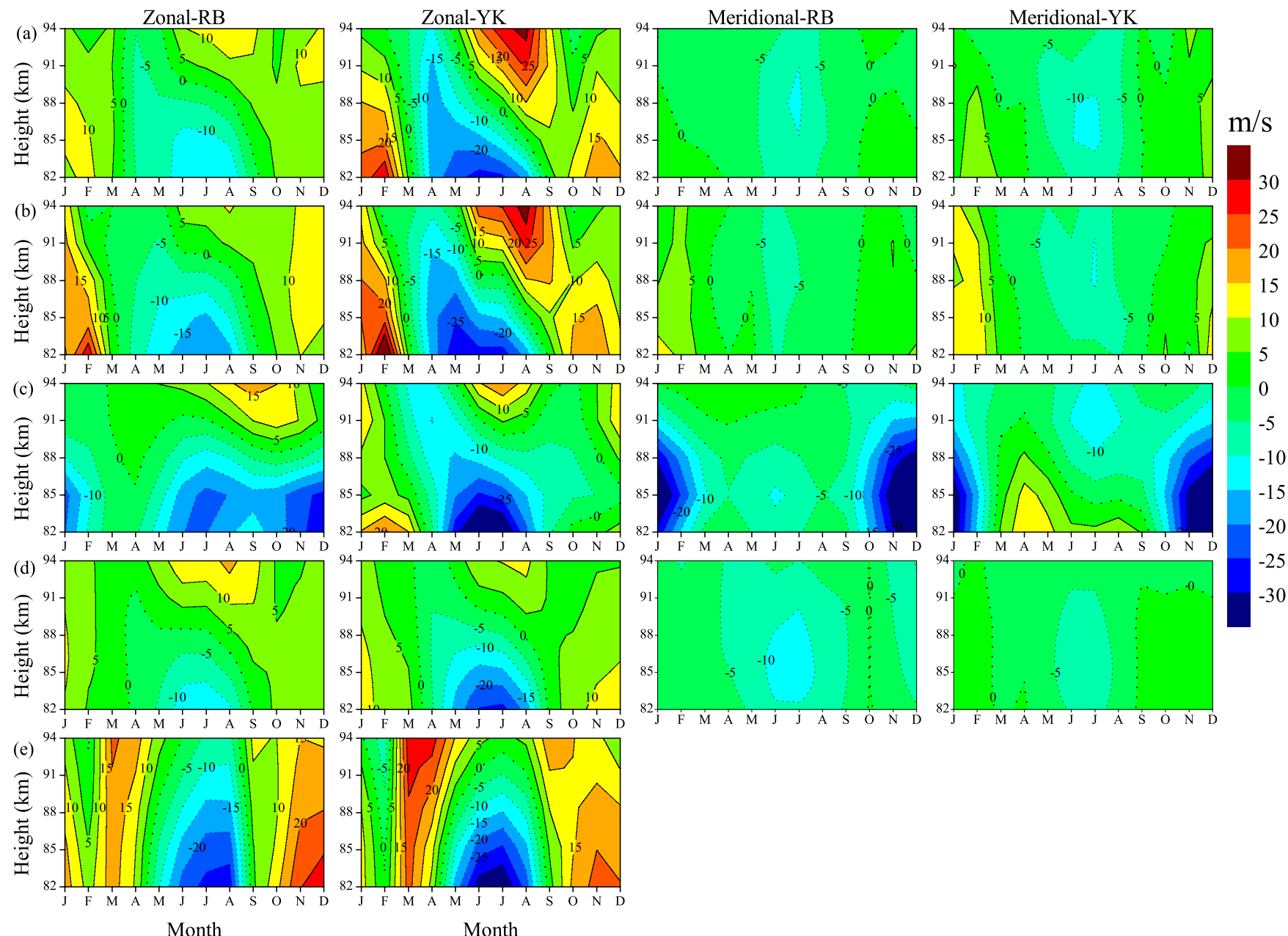

Fig. 2. Monthly variations of zonal wind at RB, YK, meridional wind at RB, YK for (a) climatological mean of observations, (b) for the period August 2005-July 2006, (c) HWM07, (d) GEWM, and (e) CIRA 86. Details are mentioned in the text.

showed strong westward winds with a typical amplitude of $20 \mathrm{~m} \mathrm{~s}^{-1}$ at $82 \mathrm{~km}$, and a peak eastward wind with amplitude $10 \mathrm{~m} \mathrm{~s}^{-1}$. Mitchell et al. (2002) observed strong westward winds of $25 \mathrm{~m} \mathrm{~s}^{-1}$ at $82 \mathrm{~km}$ and strong eastward wind with peak amplitude $30 \mathrm{~m} \mathrm{~s}^{-1}$ around $98 \mathrm{~km}$ over Esrange $\left(68^{\circ} \mathrm{N}\right)$ using SKiYMET meteor radar observations for the period August 1999-July 2000. Hocking (2001) show that the peak amplitude of the summer westward wind is around $10 \mathrm{~m} \mathrm{~s}^{-1}$ at $82 \mathrm{~km}$. A strong eastward wind with peak amplitude around $27 \mathrm{~m} \mathrm{~s}^{-1}$ at $98 \mathrm{~km}$ is seen based on the RB $\left(75^{\circ} \mathrm{N}\right)$ observations made during May 1998 to April 1999. Kishore et al. (2002), using MF radar observations, also observed a peak amplitude of the summer westward wind of around $25 \mathrm{~m} \mathrm{~s}^{-1}$ at $82 \mathrm{~km}$ altitude and an eastward wind about $5 \mathrm{~m} \mathrm{~s}^{-1}$ at $98 \mathrm{~km}$ over Poker Flat $\left(65^{\circ} \mathrm{N}\right)$ for the period October 1998-December 2000.

In the present study, we found that the peak amplitude of the summer westward wind component is around $10 \mathrm{~m} \mathrm{~s}^{-1}$ over RB $\left(75^{\circ} \mathrm{N}\right), 25 \mathrm{~m} \mathrm{~s}^{-1}$ over $\mathrm{YK}\left(62.5^{\circ} \mathrm{N}\right)$ at $82 \mathrm{~km}$ and the peak eastward wind reaches $10 \mathrm{~m} \mathrm{~s}^{-1}$ over RB and $25 \mathrm{~m} \mathrm{~s}^{-1}$ over YK at higher altitudes. This indicates that the westward flow is latitudinally dependent and generally decreases as latitude increases (moving towards the pole). A rare exception to this rule was observed by Hall et al. (2003), who showed summer westward peak values around $20 \mathrm{~m} \mathrm{~s}^{-1}$ at $82 \mathrm{~km}$ over Svalbard $\left(78^{\circ} \mathrm{N}\right)$ by meteor radar, and $25 \mathrm{~m} \mathrm{~s}^{-1}$ over Troms $\varnothing\left(70^{\circ} \mathrm{N}\right)$ using MF radar for the period 20012002 and 1996-2002, respectively. The peak amplitude in the summer eastward wind is around $10 \mathrm{~m} \mathrm{~s}^{-1}$ for the both Svalbard and Troms $\varnothing$. A particularly striking point observed in the summer zonal flow is the asymmetric nature of the zonal wind reversal, which is also observed in all the earlier observations mentioned above.

During winter months, the zonal wind over both the sites is eastward with larger values at lower heights compared to upper heights. The maximum eastward wind over RB is around $10 \mathrm{~m} \mathrm{~s}^{-1}$ and exceeds $15 \mathrm{~m} \mathrm{~s}^{-1}$ at YK. Earlier observations over RB by Hocking (2001) showed the peak amplitude is 
$\sim 12 \mathrm{~m} \mathrm{~s}^{-1}$ but at higher heights than our long term observations reveal. This difference may be due to the smaller data set used for the earlier study, or may be dependent on the observational period. The present winter flow agrees well with observations made by Manson and Meek (1991) over Troms $\varnothing$, Mitchell et al. (2002) over Esrange, Kishore et al. (2002) over Poker Flat, and Hall et al. (2003) over Svalbard and Troms $\varnothing$, with a small difference in magnitude. Possible reasons for these differences will be discussed later. During equinoxial months, the transition of summer to winter flow and vice versa is clearly seen.

Inspection of the zonal wind contours over both sites shows that strong vertical shears in the horizontal wind are observed during the summer months. In this period, the wind velocity changes from less than $-10 \mathrm{~m} \mathrm{~s}^{-1}$ at $82 \mathrm{~km}$ to $15 \mathrm{~m} \mathrm{~s}^{-1}$ at $98 \mathrm{~km}$ for RB and for YK it changes from less than $-20 \mathrm{~m} \mathrm{~s}^{-1}$ at $82 \mathrm{~km}$ to more than $30 \mathrm{~m} \mathrm{~s}^{-1}$ at $98 \mathrm{~km}$. At $\mathrm{RB}$, the wind shear at the zero wind line is around $3 \mathrm{~m} \mathrm{~s}^{-1} \mathrm{~km}^{-1}$, whereas for YK the average wind shear is around $4 \mathrm{~m} \mathrm{~s}^{-1} \mathrm{~km}^{-1}$ with peak wind shear $\sim 6 \mathrm{~m} \mathrm{~s}^{-1} \mathrm{~km}^{-1}$ near $82-85 \mathrm{~km}$. In contrast to the summer months, the winter months have reduced wind shears over both the sites. Over $\mathrm{RB}$, the average wind shear is around $2 \mathrm{~m} \mathrm{~s}^{-1} \mathrm{~km}^{-1}$, with higher values at upper heights compared to the lower heights. Over YK, the average wind shear is around $3 \mathrm{~m} \mathrm{~s}^{-1} \mathrm{~km}^{-1}$ and is almost uniform in all height regions. During the equinoxes, the wind shear is of only modest magnitude over both sites.

Coming to the meridional wind observations, over RB the meridional wind is equatorward (southward) throughout all months except for a few height regions during the winter when it is poleward (northward) with less magnitude. In comparison to the RB observations, the winter meridional flow over YK is poleward with considerable magnitude. Similarly to RB, the YK summer meridional flow is equatorward. It is clearly seen that there is an equatorward jet below $90 \mathrm{~km}$ during June and July over both sites. The magnitude of the jet is around $8 \mathrm{~m} \mathrm{~s}^{-1}$ over RB and $10 \mathrm{~m} \mathrm{~s}^{-1}$ over YK. On average, the meridional flow over RB is weaker than YK. Earlier observations (Hocking, 2001) over RB showed that the meridional flow is equatorward throughout the year and at all heights, with weak wind flow during winter and strong wind flow during summer with an equatorward jet about $20 \mathrm{~m} \mathrm{~s}^{-1}$. Manson and Meek (1991) observed a summer equatorward jet with an amplitude of $5 \mathrm{~m} \mathrm{~s}^{-1}$ over Troms $\varnothing$ and they also observed poleward winds during a few months with smaller magnitude. Hall et al. (2003) observed equatorward winds over Svalbard and Troms $\varnothing$ with a summer equatorward jet of amplitude $6 \mathrm{~m} \mathrm{~s}^{-1}$. Mitchell et al. (2002) also observed a completely equatorward wind except during equinoxes (poleward flow with less amplitude $<2 \mathrm{~m} \mathrm{~s}^{-1}$ ) and they also found a summer equatorward jet during June and July with an amplitude of $12 \mathrm{~m} \mathrm{~s}^{-1}$. Kishore et al. (2002) found a summer equatorward jet with an amplitude of $8 \mathrm{~m} \mathrm{~s}^{-1}$ over Poker Flat and strong poleward flow during the winter season.
Unlike the zonal wind shear, the meridional wind shear is very modest in size since the meridional wind is almost uniform throughout the height region. Inspection of both zonal and meridional winds shows that the equatorward jet occurs at heights where a strong zonal wind shear exists.

Since the longest period of continuous overlap between the two sites is 2005-2006, we have plotted the winds during August 2005-July 2006 in Fig. 2b. This is to verify the similarity between the two sites during common data coverage. Generally, the gross features are the same as observed from climatological means (Fig. 2a), with some exceptions in magnitude especially in January and February.

\subsection{Mean winds - inter annual variation}

The difference between the amplitudes of the observations discussed above can be attributed to either differences in the observational systems, latitudinal differences, longitudinal differences and any difference in the time span of the observations used for the studies. Manson et al. (1992) identified a $35 \%$ reduction in the MF radar winds compared to other observational techniques. Jacobi et al. (2009) identified the difference between MF radar and meteor radar increases above $80 \mathrm{~km}$ and the MF radar winds show smaller values than the meteor winds, which needs to be recognized when comparing our data to previous MF measurements. The comparison between RB and YK will help us to identify the latitudinal variation. In order to identify the time dependence it is better to look at the monthly variation over multiple years, which will give an idea about year to year variation. Figure 3 illustrates the monthly mean zonal and meridional winds over RB and YK during the periods June 1997 to February 2009 and June 2002 to October 2008, respectively. The figure enables us to study inter-annual variation over all the heights. In order to identify any possible solar cycle dependence of the zonal and meridional winds, we have also plotted the monthly means of the $10.7 \mathrm{~cm}$ solar flux, a proxy for solar cycle activity, at the bottom of the figure. Here we used a 12 point smoothed solar flux in order to suppress the monthly variations.

The zonal winds over RB and YK show similar variations with larger magnitude over YK than RB. The zonal wind flow shows clear seasonal variations, as mentioned above. Another important point to notice here is the year to year variation of the mean winds. For example, at higher heights the RB zonal winds are more positive during the increasing phase of the solar cycle than during the decreasing phase of the solar cycle. During the period of solar maximum, the RB zonal winds at higher heights are less compared to the other years. At lower heights, the zonal wind during summer months showed an increasing tendency in westward wind over both RB and YK. As the zonal wind, the meridional wind showed clear interannual variability over both the sites RB and YK. The RB meridional winds are almost all equatorward in all heights and all seasons before the solar 


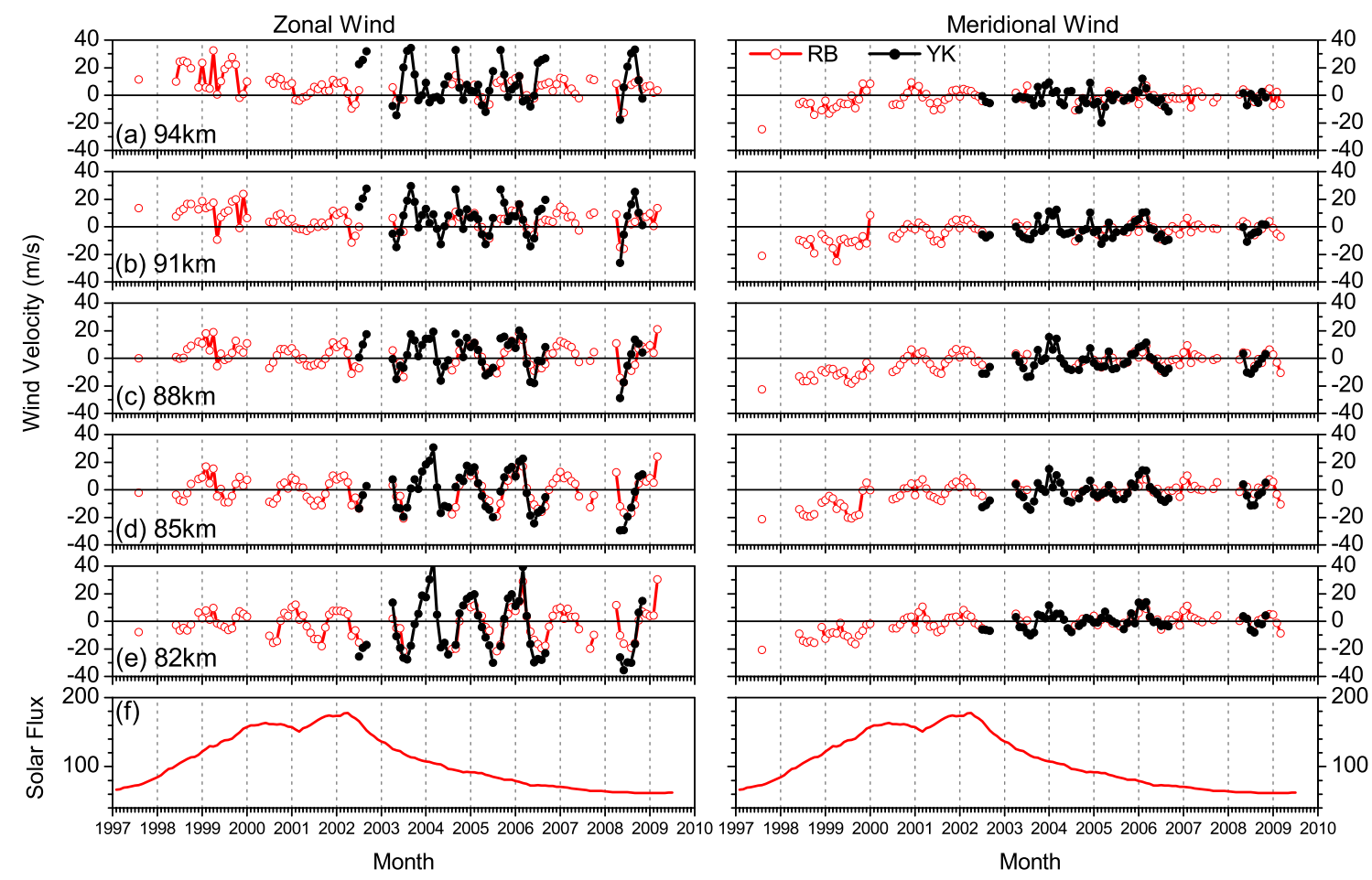

Fig. 3. (a-e) Monthly variation of the zonal and meridional winds over RB (red line with open circles) and YK (black line with filled circles) for the period 1997-2009 for heights $94,91,88,85$, and $82 \mathrm{~km}$, respectively. (f) Monthly variation of a 12 point smoothed monthly solar flux for the period 1997-2009.

maximum, while after the solar maximum the meridional flow is poleward during some of the winter months. In contrast to the increasing tendency in summer westward flow in the zonal wind, the meridional winds show a decreasing tendency. The most important point observed in the meridional wind flow is the variation in the summer equatorward jet amplitude. It has a large amplitude before the solar maxima (before 2001), so the observations made by Hocking (2001) revealed strong summer equatorward jet with $20 \mathrm{~m} \mathrm{~s}^{-1}$. It may not be an artifact because such a strong equatorward jet with speeds of more than $12 \mathrm{~m} \mathrm{~s}^{-1}$ has been observed by Mitchell et al. (2002) for the observational period August 1999-July 2000 over Esrange $\left(68^{\circ} \mathrm{N}\right)$. At the same time, the YK meridional wind flow also showed large inter-annual variability in amplitude of the summer equatorward jet.

At all heights, the observations showed clear annual variation in both zonal and meridional winds over RB and YK. In order to quantify other oscillations, the monthly mean values of both wind components from each height have been subjected to Lomb-Scargle Periodogram (LSP) analysis (Lomb, 1976; Scargle, 1982). LSP analysis allows simultaneous estimation of the amplitude, phase and significance level for the spectral components and works even though we have data gaps. From the LSP analysis, we found that an annual oscillation is dominant. The amplitudes of annual oscillation are listed in Table 2. From Table 2, it is clear that the annual os- cillation has considerable amplitude in the zonal wind in all height regions, but for the meridional winds it is confined to the lower height region (below $91 \mathrm{~km}$ ). The maximum amplitude in annual oscillation over both sites occurs at $85 \mathrm{~km}$. Larger amplitudes are observed over YK than RB both in the zonal and meridional components, at least below $92 \mathrm{~km}$. The differences in amplitudes indicate that there is a latitudinal variation in the annual oscillation amplitude. In addition to the annual oscillation, the zonal component shows a dominant semiannual oscillation over both stations RB (from $91 \mathrm{~km}$ and above) and YK (from $85 \mathrm{~km}$ and above).

\subsection{Mean winds - comparison with models}

In this section, we consider comparisons made between observations and different models viz., HWM07, GEWM and CIRA-86. The HWM07, GEWM and CIRA-86 model winds over the selected sites are illustrated in Fig. $2 c, d$ and e, respectively. Since CIRA-86 provides only zonal wind observations, Fig. 2e contains only zonal wind.

The HWM07 model winds over RB and YK are illustrated in Fig. 2c. As mentioned above, HWM07 is the extended version of HWM93 and this model was developed based on 50 years of satellite, rocket, and ground based wind measurements (Drob et al., 2008). The model and observations have both similarities and differences. For example, the model 
Table 2. Amplitudes of Annual oscillation of mean Wind; Diurnal Tide amplitude (DTA), phase (DTPh); Semidiurnal Tide amplitude (SDTA), phase (SDTPh); and Terdiurnal Tide amplitude (TDTA), phase (TDTPh) for both zonal and meridional components over Resolute Bay (RB) and Yellowknife (YK). Note that the highlighted values have more than an $80 \%$ significance level.

\begin{tabular}{lllrrrrr}
\hline Station & Parameter & Component/ht & $82 \mathrm{~km}$ & $85 \mathrm{~km}$ & $88 \mathrm{~km}$ & $91 \mathrm{~km}$ & $94 \mathrm{~km}$ \\
\hline RB & Wind & Zonal & $\mathbf{1 2 . 4 2}$ & $\mathbf{1 1 . 7 7}$ & $\mathbf{8 . 8 3}$ & $\mathbf{5 . 8 7}$ & $\mathbf{5 . 5 3}$ \\
& & Meridional & $\mathbf{4 . 3 6}$ & $\mathbf{5 . 1 0}$ & $\mathbf{4 . 3 5}$ & $\mathbf{3 . 1 4}$ & $\mathbf{2 . 5 8}$ \\
& DTA & Zonal & $\mathbf{2}$ & $\mathbf{2 . 2 6}$ & $\mathbf{2 . 2 6}$ & $\mathbf{2 . 1 2}$ & $\mathbf{2 . 8 8}$ \\
& Meridional & $\mathbf{1 . 4 7}$ & $\mathbf{1 . 8 8}$ & $\mathbf{1 . 5 2}$ & $\mathbf{1 . 9 2}$ & 1.17 \\
& DTPh & Zonal & 1.38 & $\mathbf{2 . 9 6}$ & $\mathbf{2 . 5 7}$ & $\mathbf{2 . 1 8}$ & $\mathbf{1 . 7 8}$ \\
& Meridional & 0.66 & $\mathbf{1 . 7 7}$ & $\mathbf{1 . 4 5}$ & $\mathbf{1 . 8 2}$ & $\mathbf{2 . 3 8}$ \\
& SDTA & Zonal & $\mathbf{2 . 2 3}$ & 2 & 1.84 & 1.97 & 2.06 \\
& Meridional & $\mathbf{1 . 9 4}$ & 1.79 & 1.45 & 1.41 & 1.73 \\
& SDTPh & Zonal & 0.64 & 0.87 & 0.71 & 0.80 & 0.24 \\
& Meridional & 0.79 & $\mathbf{0 . 8 9}$ & 0.85 & 0.50 & 0.62 \\
& TDTA & Zonal & 0.37 & 0.29 & 0.46 & 0.50 & 0.53 \\
& Meridional & 0.12 & 0.38 & 0.32 & 0.46 & 0.92 \\
& TDTPh & Zonal & 1.03 & $\mathbf{1 . 1 1}$ & 0.86 & $\mathbf{1 . 2 7}$ & $\mathbf{1 . 1 1}$ \\
& Meridional & $\mathbf{1 . 1 1}$ & $\mathbf{1 . 5 9}$ & 1.06 & 0.64 & 0.35 \\
YK & Wind & Zonal & $\mathbf{2 7 . 0 8}$ & $\mathbf{1 8 . 7 1}$ & $\mathbf{1 2 . 2 5}$ & $\mathbf{1 2 . 0 4}$ & $\mathbf{1 5 . 1 4}$ \\
& Meridional & $\mathbf{6 . 3 1}$ & $\mathbf{8 . 1 3}$ & $\mathbf{7 . 7 8}$ & $\mathbf{6 . 0 8}$ & 2.52 \\
& DTA & Zonal & $\mathbf{3 . 2 6}$ & $\mathbf{1 . 2 1}$ & $\mathbf{1 . 4 7}$ & 0.99 & 2.16 \\
& Meridional & $\mathbf{4 . 4 5}$ & $\mathbf{5 . 5 5}$ & $\mathbf{5 . 3 9}$ & $\mathbf{5 . 9 7}$ & $\mathbf{7 . 5 3}$ \\
& DTPh & Zonal & $\mathbf{3 . 1 7}$ & $\mathbf{4 . 8 9}$ & 1.83 & $\mathbf{1 . 4 8}$ & $\mathbf{1 . 6 8}$ \\
& Meridional & 0.74 & 0.57 & 1.04 & 0.58 & 0.42 \\
& SDTA & Zonal & 2.93 & 4.08 & $\mathbf{5 . 6 0}$ & $\mathbf{8 . 1 2}$ & $\mathbf{1 0 . 1 4}$ \\
& Meridional & 2.22 & 3.79 & $\mathbf{6 . 8 4}$ & $\mathbf{8 . 3 9}$ & $\mathbf{8 . 6 9}$ \\
& SDTPh & Zonal & 1.12 & $\mathbf{1 . 7 3}$ & $\mathbf{1 . 5 4}$ & 0.83 & 0.47 \\
& Meridional & $\mathbf{2 . 0 9}$ & $\mathbf{1 . 7 8}$ & $\mathbf{1 . 2 7}$ & 0.84 & 0.75 \\
& TDTA & Zonal & 1.06 & 0.93 & 1.39 & $\mathbf{1 . 8 0}$ & $\mathbf{1 . 3 6}$ \\
& Meridional & $\mathbf{1 . 4 0}$ & 0.94 & $\mathbf{1 . 5 7}$ & $\mathbf{2 . 5 1}$ & $\mathbf{2 . 8 9}$ \\
& TDTPh & Zonal & 1.19 & $\mathbf{1 . 9 5}$ & $\mathbf{1 . 9 0}$ & 0.71 & 1.59 \\
& Meridional & 1.02 & 0.89 & 1.28 & 0.69 & $\mathbf{1 . 3 1}$ \\
\hline & & & & & & & \\
& & & & & \\
& & & & &
\end{tabular}

represents the summer zonal wind flow pattern as evident in the observations, but with a noticeable difference in magnitude. The model summer meridional flow shows an equatorward jet, as also evident in the observations. However, the model winds during the winter season show a different picture than the observations. For example, the model winter zonal winds show westward flow which is not evident in the observations. The model winds particularly fail to represent the winter zonal flow at RB, but perform better at YK for at least the later winter months (January-February). The model winter meridional winds show stronger equatorward flow over both sites, which is not evident in the observations. Even though the model was based on 50 years of data, data points were often sparse over North American latitudes, which may be the one of the reason for these differences. It may be important that the HWM07 data were recorded at different longitudes, whereas RB and YK are in the Northern American sector only.

The GEWM winds are zonal means in the height region 70 to $100 \mathrm{~km}$ with $1 \mathrm{~km}$ resolution and with $2.5^{\circ}$ latitude resolution from $90^{\circ} \mathrm{S}$ to $90^{\circ} \mathrm{N}$. The model is constructed from the fitting of monthly mean winds from meteor radar and MF radar measurements at more than 45 stations, well distributed over the globe. The monthly mean winds predicted by GEWM for $75^{\circ} \mathrm{N}$ (for RB) and $62.5^{\circ} \mathrm{N}$ (for YK) are presented in Fig. 2d. Note that the gross features like the summer mesospheric westward jet, summer eastward flow at higher altitudes and the winter eastward wind are similar to the observations. The model includes the RB observations for the time span 1997-2001 (see Table 1 in Portnyagin et al., 2004). Nevertheless it does not fully represent the mean structure over RB, with the model winds showing stronger eastward wind over $75^{\circ} \mathrm{N}$ than $62.5^{\circ} \mathrm{N}$, which is not evident in observations. The model meridional winds are also in good agreement, but the equatorward jet is stronger over $75^{\circ} \mathrm{N}$ than $62.5^{\circ} \mathrm{N}$. These differences may be due to the smaller amount of data entered into the model. Less than 3 years of observations, except for the Troms $\varnothing$ MF radar observations, have been used in the model development (see Table 1 in Portnyagin et al., 2004). This may be one of 
the possible reasons for the considerable difference between model winds and observations, since the MLT winds have large inter annual variability, as shown in Fig. 3. Longitudinal variability may also play a role.

Unlike HWM07 and GEWM, the CIRA-86 model atmosphere provides only zonal winds, and these are zonal means with 71 height steps and $5^{\circ}$ latitude steps from $80^{\circ} \mathrm{S}$ to $80^{\circ} \mathrm{N}$. For the comparison, the average of $60^{\circ} \mathrm{N}$ and $65^{\circ} \mathrm{N}$ $\left(62.5^{\circ} \mathrm{N}\right)$ zonal winds is taken as representative of CIRA86 for $\mathrm{YK}$, and the $75^{\circ} \mathrm{N}$ zonal winds are used for RB. The monthly means of the CIRA 86 zonal winds are presented in Fig. 2e for the height region of 82 to $98 \mathrm{~km}$. Both model and observations reveal similar summer mesospheric westward jets over both sites. But there are noticeable differences in magnitude between the observed winds and model winds. The model summer winds show westward flow in all heights and there is no eastward flow, in contrast to the observations. The model winds show eastward flow above $90 \mathrm{~km}$ at $62.5^{\circ} \mathrm{N}$ and above $98 \mathrm{~km}$ at $75^{\circ} \mathrm{N}$. Apart from this, a model winds over the two sites show similar behavior. Note that the model winds show a latitudinal variation, with stronger winds at $62.5^{\circ} \mathrm{N}$ than at $75^{\circ} \mathrm{N}$. This supports the latitudinal variation of the summer mesospheric westward jet as evident in the observations. Even though the winter months, except February, show eastward flow similar to observations, the model winds overestimate the observations. During the month of February, there is a westward flow above $85 \mathrm{~km}$ which is not evident in the observations. During equinoxes, the model winds show strong eastward wind and the equinoxes do not show any smooth seasonal change as presented in the observations.

A significant point in regard to the CIRA-86 model is that it has a much weaker wind shear in the summer flow in comparison to that observed by the radar. The wind shear is around 50\% of the observed values in the case of $\mathrm{RB}$, whereas over YK it is less than $50 \%$ of the observations. In the CIRA- 86 model at $75^{\circ} \mathrm{N}$, the zero-wind line in the summer zonal wind rises to above $96 \mathrm{~km}$ rapidly as summer progresses. In contrast, the observations place the zero line at heights around $91 \mathrm{~km}$ for most of the summer months. At $62.5^{\circ} \mathrm{N}$, the CIRA 86 model winds show the zero line around $90 \mathrm{~km}$ during the middle of the summer month and descending to lower heights $(<82 \mathrm{~km})$ in other months symmetrically to midsummer. In contrast to the model winds, the observations show the zero line peaks above $98 \mathrm{~km}$, starting during the spring equinox and descending to $82 \mathrm{~km}$ before September. There is no symmetric zero line variation in the observations as provided in the model winds. In other words, the asymmetric nature of the summer zonal wind reversal is missing in the model winds.

\subsection{Tides - composite monthly mean variation}

In this section, we discuss the tides over northern polar latitudes. We mainly focus on diurnal and semidiurnal tides, and focus less on terdiurnal tides. Diurnal and semidiurnal tides have been studied at many latitudes, but less so at polar latitudes. The terdiurnal (8-h) tide is not well defined and studies made over different latitudes are described using different explanations. Teitelbaum et al. (1989) and Smith (2000) suggest that it is due to nonlinear interactions between the diurnal and semidiurnal tide. According to Miyahara and Forbes (1991), it is due to the interaction between the diurnal tide and gravity waves.

By using composite least square fits, as mentioned in the Sect. 2, the amplitudes and phases of the diurnal $(24 \mathrm{~h})$, semidiurnal $(12 \mathrm{~h})$ and terdiurnal $(8 \mathrm{~h})$ tides have been extracted for each month. The relative amplitudes of the zonal and meridional components of the tides give information about the polarization of the tide. For example, if the amplitudes of the zonal component and the meridional component are equal then the tidal wave is circularly polarized. If the amplitude of one component is larger than the other then the tide is elliptically polarized. The phase of the tide is defined as the time of the first maximum of eastward or northward wind for the appropriate component and is measured in local time. Modes are in phase quadrature if the phases of the two components differ by a quarter of the total period. The rate of change of phase with height can be used to determine the vertical wavelength (Hocking, 2001). If the phase gradients are not uniform it may indicate the existence of multiple tidal modes. Quasi- randomness in the phase profile occurs due to the superposition of different tidal modes, and these types of profiles are observed often (Tsuda et al., 1983; Thayaparan, 1997, and references therein). This may happen due to the combination of forcing in the troposphere/stratosphere and in situ forcing in the upper mesosphere/lower thermosphere, for example, or due to mixing of migrating and non migrating tides (Ward et al., 2005). Generally, the vertical wavelengths can only be calculated for uniform phase profiles which do not contain sudden changes with height. A linear fit to the phase profile can then be used to determine the vertical wavelength.

The composite tidal amplitudes and phases from each month are used to generate the climatological monthly means by using a vector averaging (Grieger et al., 2002). Those climatological monthly means of diurnal, semidiurnal and terdiurnal tides for both zonal and meridional components over RB and YK are depicted in Fig. 4. The diurnal, semidiurnal and terdiurnal amplitudes and phases of RB observations are shown in Fig. 4a, b and c, respectively. Figure 4d, e, and $\mathrm{f}$ is the same as $4 \mathrm{a}-\mathrm{c}$ but for YK. Details are discussed in the caption of Fig. 4. The main features observed from Fig. 4 are listed in Table 3. Details of those features are discussed below. 


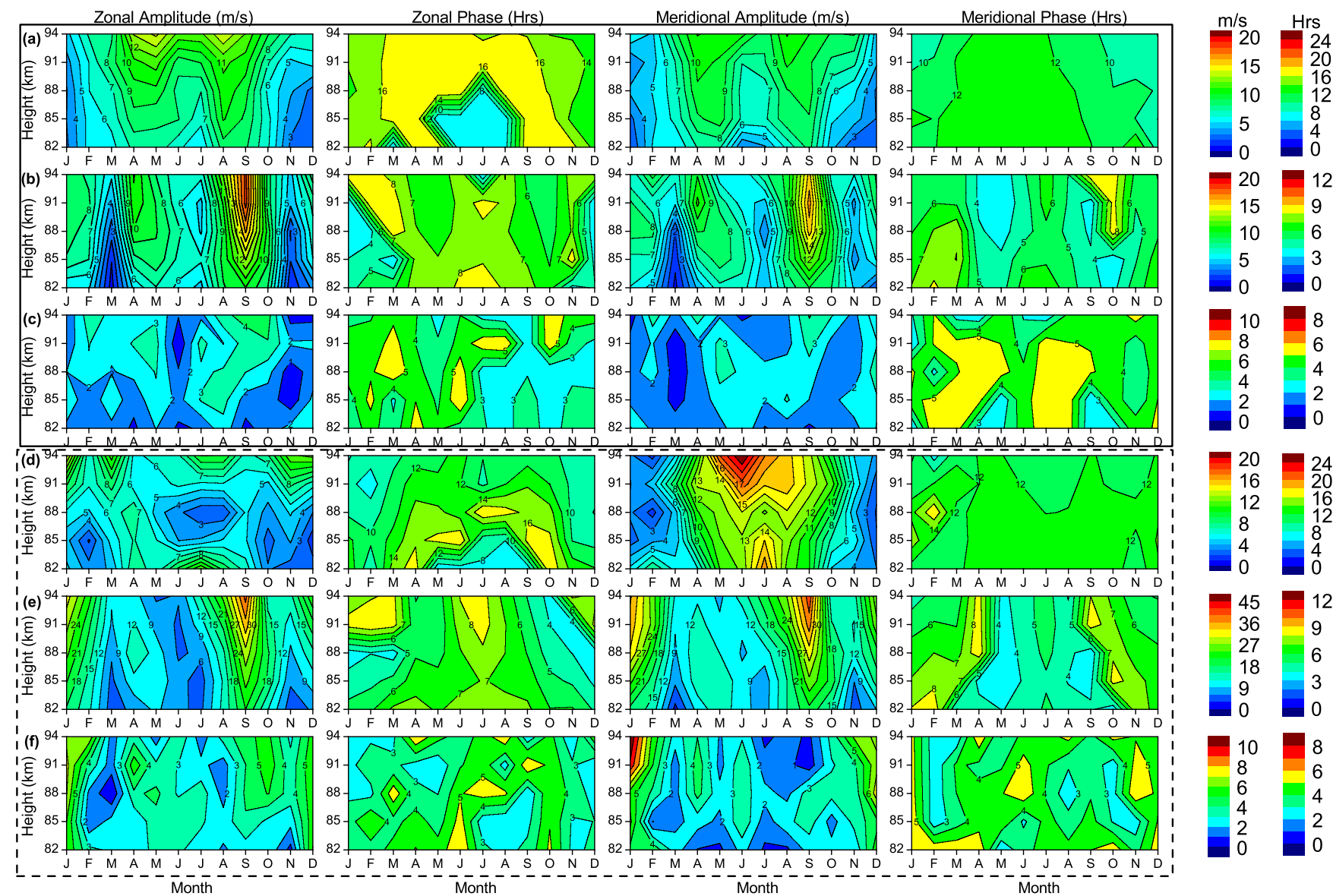

Fig. 4. Climatological monthly mean variations of zonal amplitude, zonal phase, meridional amplitude, and meridional phase (a-c) for diurnal, semidiurnal and terdiurnal tide over RB. (d-f) similar to $(\mathrm{a}-\mathrm{c})$ but for YK. Note that the first color bar is meant for amplitude and the second color bar is meant for phase.

The diurnal tide show different behavior over the two sites. The diurnal tidal amplitudes of the zonal and meridional components are the same over RB, but differ over YK. The diurnal tidal amplitudes over RB show a seasonal variation with maximum amplitudes $\left(8-15 \mathrm{~m} \mathrm{~s}^{-1}\right)$ during equinoxes, followed by summer $\left(7-13 \mathrm{~m} \mathrm{~s}^{-1}\right)$, and minimum amplitudes $\left(3-5 \mathrm{~m} \mathrm{~s}^{-1}\right)$ during winter. Over YK, the meridional amplitudes are stronger than the zonal amplitudes. The zonal amplitudes show peak values above $90 \mathrm{~km}$ throughout the year while at lower altitudes, peak values are observed during spring equinox and summer. In contrast to the zonal amplitudes, the meridional amplitudes show seasonal variation with larger amplitudes $\left(13-17 \mathrm{~m} \mathrm{~s}^{-1}\right)$ during summer and minimum amplitudes $\left(5 \mathrm{~m} \mathrm{~s}^{-1}\right)$ during winter. The amplitudes observed over YK support the observations made at Poker Flat and Norway by Avery et al. (1989) and at Esrange by Mitchell et al. (2002). The difference between zonal and meridional amplitudes is larger than observed by Mitchell et al. (2002) and may be due to interannual variability and difference in latitude and longitude.
Over RB, the phase contours show that the diurnal tidal vector is circularly polarized and rotates in a clockwise direction during summer in lower heights and anticlockwise at upper heights during summer and in all heights during winter. The diurnal tidal vector over YK shows a seasonal variation. It is circularly polarized and rotates in the clockwise direction during winter, and elliptically polarized and rotates in the anticlockwise direction during summer. The vertical wavelengths in the zonal component are less during summer compared to other seasons. This is evident over both sites. The vertical wavelengths in the meridional component are broadly uniform throughout the year over both sites. The wavelengths in the meridional component are often of the order of $100-120 \mathrm{~km}$. The zonal vertical wavelengths are larger over RB than at YK. The difference between vertical wavelengths of RB and YK is larger in the zonal component than the meridional component. Manson et al. (1988) identified long vertical wavelengths throughout the year with a short wavelength occasionally during winter months. Avery et al. (1989) observed large vertical wavelengths during 
Table 3. Summary of different tidal parameters observed at Resolute Bay (RB) and Yellowknife (YK).

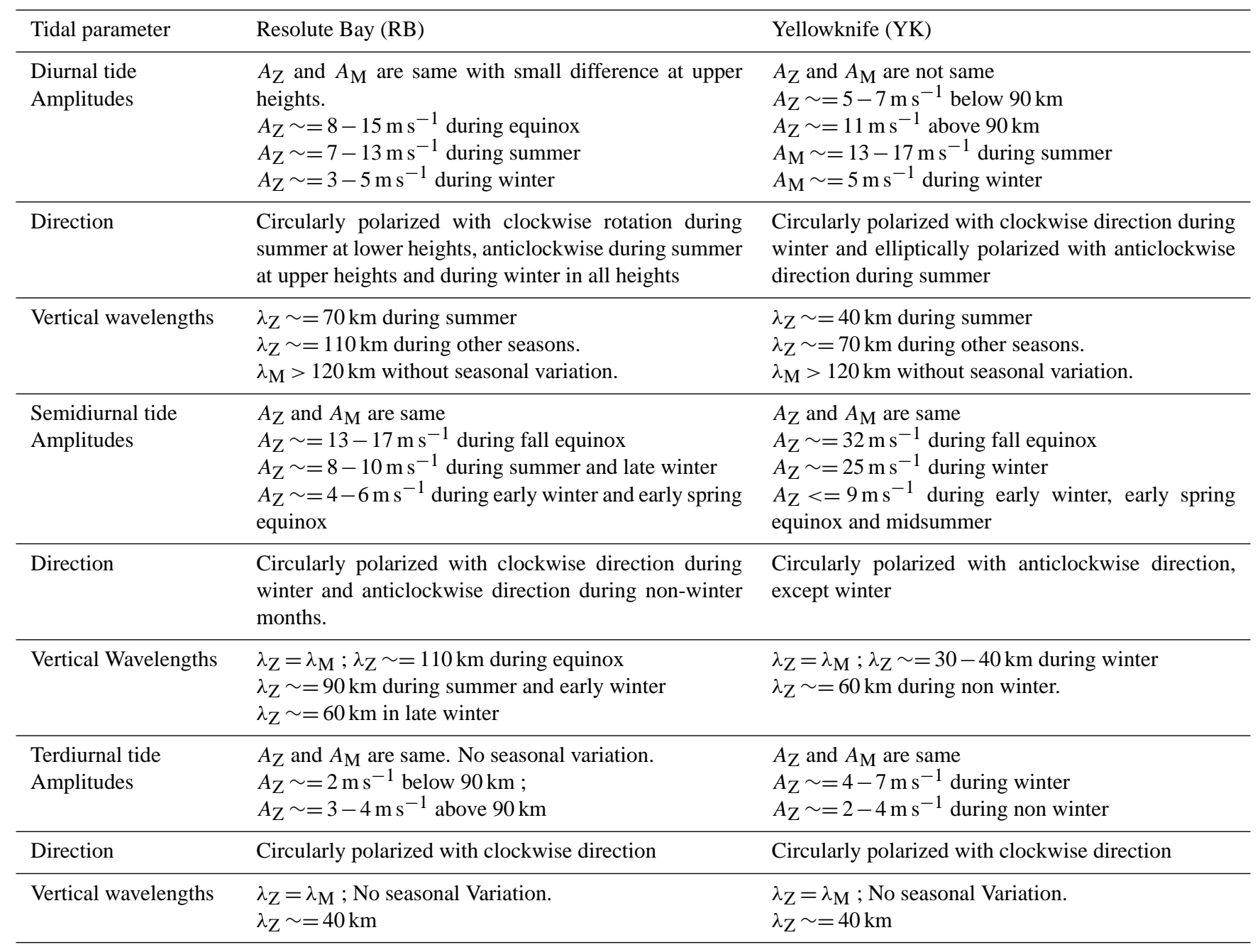

$A_{\mathrm{Z}}$ and $A_{\mathrm{M}}$ are Zonal and Meridional amplitudes, respectively. $\lambda_{\mathrm{Z}}$ and $\lambda_{\mathrm{M}}$ are Zonal and Meridional vertical wavelengths, respectively.

spring, summer and fall seasons over Poker Flat and Norway. Mitchell et al. (2002) also identified large vertical wavelengths of more than $60 \mathrm{~km}$ throughout the year, reaching nearly $115 \mathrm{~km}$ during winter over Esrange $\left(68^{\circ} \mathrm{N}\right)$ for the period 1999 to 2000.

At each site, the semidiurnal tidal amplitudes of the zonal and meridional components are approximately the same. The semidiurnal tidal amplitudes over YK are larger than (almost double) those at RB. Maximum amplitudes are observed during fall equinoxes, with peak values of about $17 \mathrm{~m} \mathrm{~s}^{-1}$ at $\mathrm{RB}$ and $32 \mathrm{~m} \mathrm{~s}^{-1}$ at YK. Over RB, the maximum amplitudes are achieved during late winter and summer, with exceptions during June and July. Minimum amplitudes are observed during early winter and early spring equinox. Over YK, the maximum amplitudes of about $25 \mathrm{~m} \mathrm{~s}^{-1}$ are reached in winter and minimum amplitudes of about $9 \mathrm{~m} \mathrm{~s}^{-1}$ are observed during early winter, early spring and midsummer. It is important to notice that the rapid growth in amplitudes during fall equinox is evident over both sites. The seasonal variations of the amplitudes agree well with the observations made over Esrange (Mitchell et al., 2002).

Over both sites the semidiurnal tidal vector is generally circularly polarized. It rotates in a clockwise direction during winter months and an anticlockwise direction during nonwinter months over RB. It rotates in an anticlockwise direction, with an exception during winter, over YK. The zonal and meridional phase contours show similar variations. Over $\mathrm{RB}$, larger vertical wavelengths $(110 \mathrm{~km})$ are observed during equinox, followed by summer and early winter months with wavelengths about $90 \mathrm{~km}$. Shorter wavelengths of about $60 \mathrm{~km}$ occur during late winter months. The vertical wavelengths observed over YK are smaller compared to RB. The YK phase contours show smaller vertical wavelengths of about $30-40 \mathrm{~km}$ during winter and larger vertical wavelengths of about $60 \mathrm{~km}$ during non winter months. 

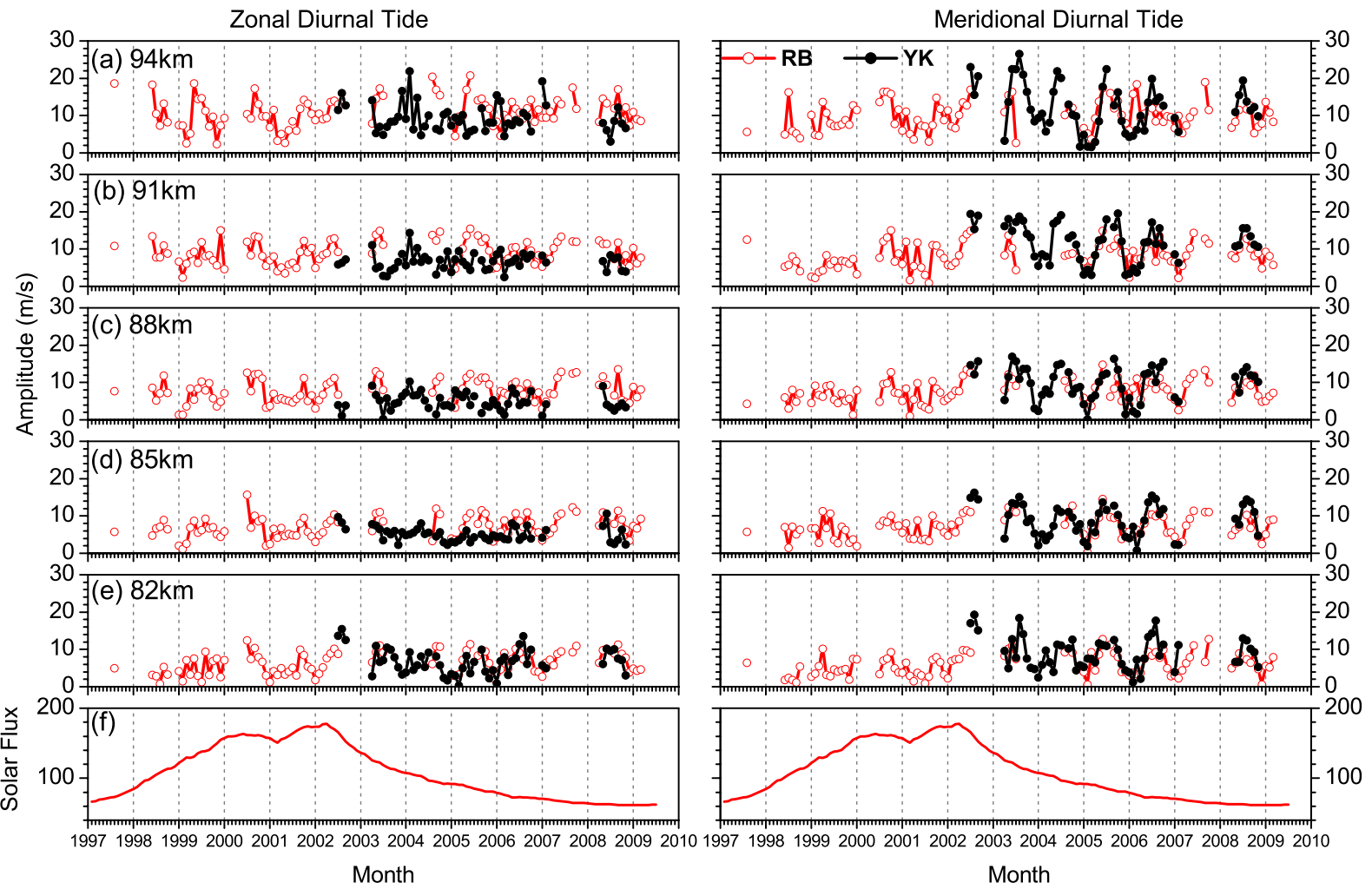

Fig. 5. Similar to Fig. 3, but for diurnal tidal amplitude.

The terdiurnal tidal amplitudes of the zonal and meridional components are similar over both stations. The terdiurnal tidal amplitudes over YK are larger than at RB. The terdiurnal tidal amplitudes are uniform over RB, with peak values of about $2 \mathrm{~m} \mathrm{~s}^{-1}$ below $90 \mathrm{~km}$ and $\sim 3-4 \mathrm{~m} \mathrm{~s}^{-1}$ above $90 \mathrm{~km}$. In contrast to RB, the terdiurnal amplitudes over YK show seasonal variation with larger amplitudes $\left(4-7 \mathrm{~m} \mathrm{~s}^{-1}\right)$ during winter and smaller amplitudes $\left(2-4 \mathrm{~m} \mathrm{~s}^{-1}\right)$ during non winter months. The observed amplitudes are comparable with the observations made over Esrange by Younger et al. (2002) for the time span of October 1999-April 2001. The terdiurnal tidal vector is circularly polarized and generally rotates in a clockwise direction over both sites. The phase contours show similar variation both in zonal and meridional components. This is also evident over both sites. The phase contours reveal the presence of small vertical wavelengths of about $40 \mathrm{~km}$. The observed vertical wavelengths also compare well with values reported over Esrange.

In order to identify the seasonal variation of the dominant tidal components out of the diurnal, semidiurnal and terdiurnal, we calculated the percentage of contribution of each tide to the total tidal power (defined as the sum of squares of the zonal and meridional amplitudes of diurnal, semidiurnal and terdiurnal tides). The diurnal and semidiurnal components are generally more than $80 \%$, with some seasonal variation, and the terdiurnal component is about $15 \%$, with little sea- sonal variation. Over $\mathrm{RB}$, the diurnal tidal contribution is dominant during spring and summer, with less contribution during fall and winter. The semidiurnal tidal contribution is just the opposite to the diurnal tidal seasonal contribution. In contrast to RB, the diurnal tide over YK has a large contribution only during summer and the semidiurnal tide has a large contribution during other seasons.

\subsection{Tides - interannual variation}

The climatological mean values shown in Fig. 4 provide the latitudinal and seasonal variation of the amplitudes and phases. However, it is better to have an idea about their interannual variability before comparing the results with model predictions. The interannual variability of the amplitudes of diurnal, semidiurnal and terdiurnal tides over RB and YK for both components is depicted in Figs. 5, 6 and 7, respectively. The monthly values of the phases are used to identify the vertical wavelengths and those results are illustrated in Fig. 8. Here we have also tried to identify the dominant oscillations in the tidal amplitudes and phases by subjecting them to LSP analysis as we did for the winds in Sect. 3.1. Since it is believed that the annual oscillation is dominant over polar latitudes, the annual oscillation amplitudes are presented in Table 2 for tidal amplitudes and phases of both components over both sites. 

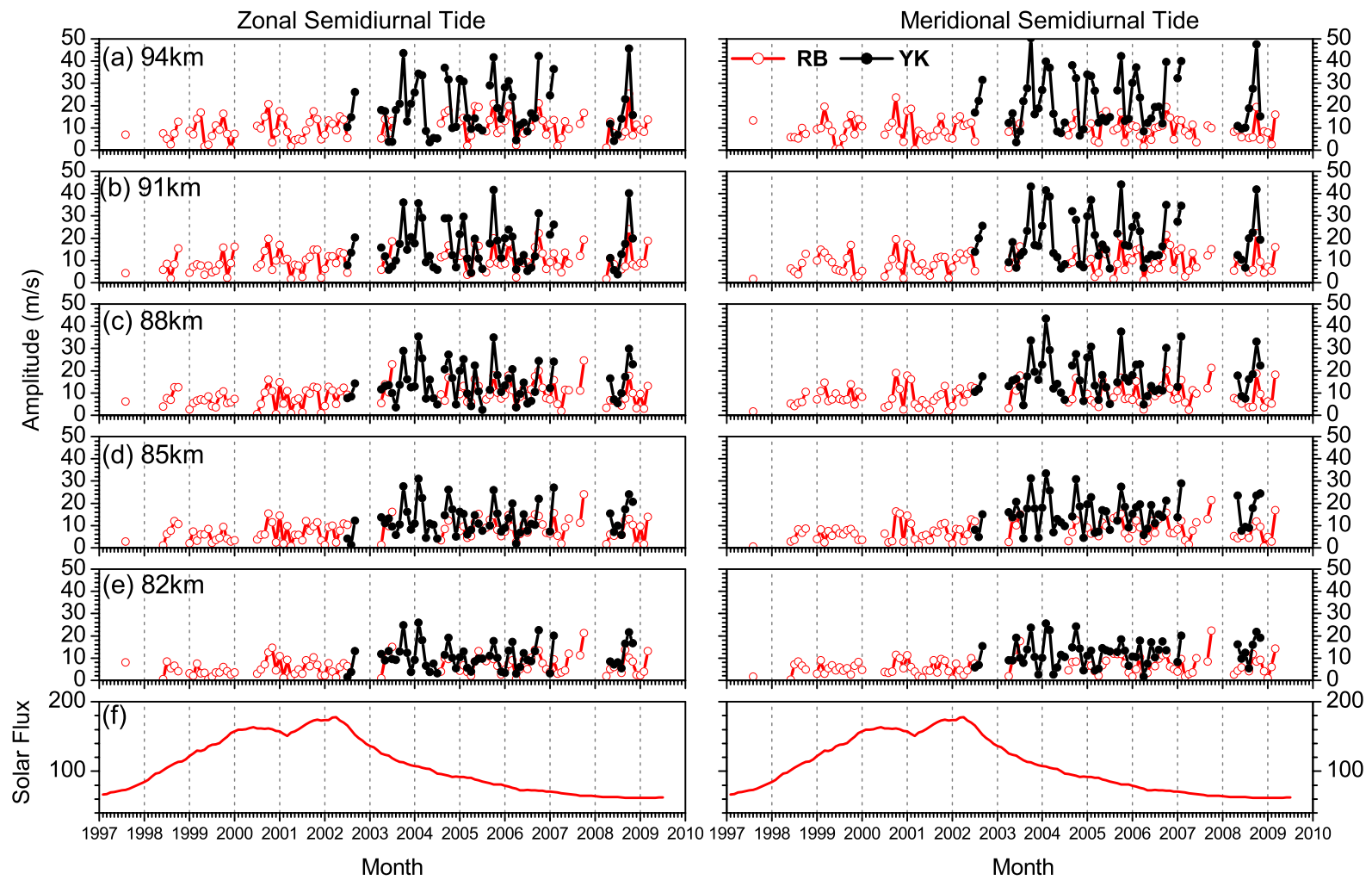

Fig. 6. Similar to Fig. 3, but for semidiurnal tidal amplitudes.

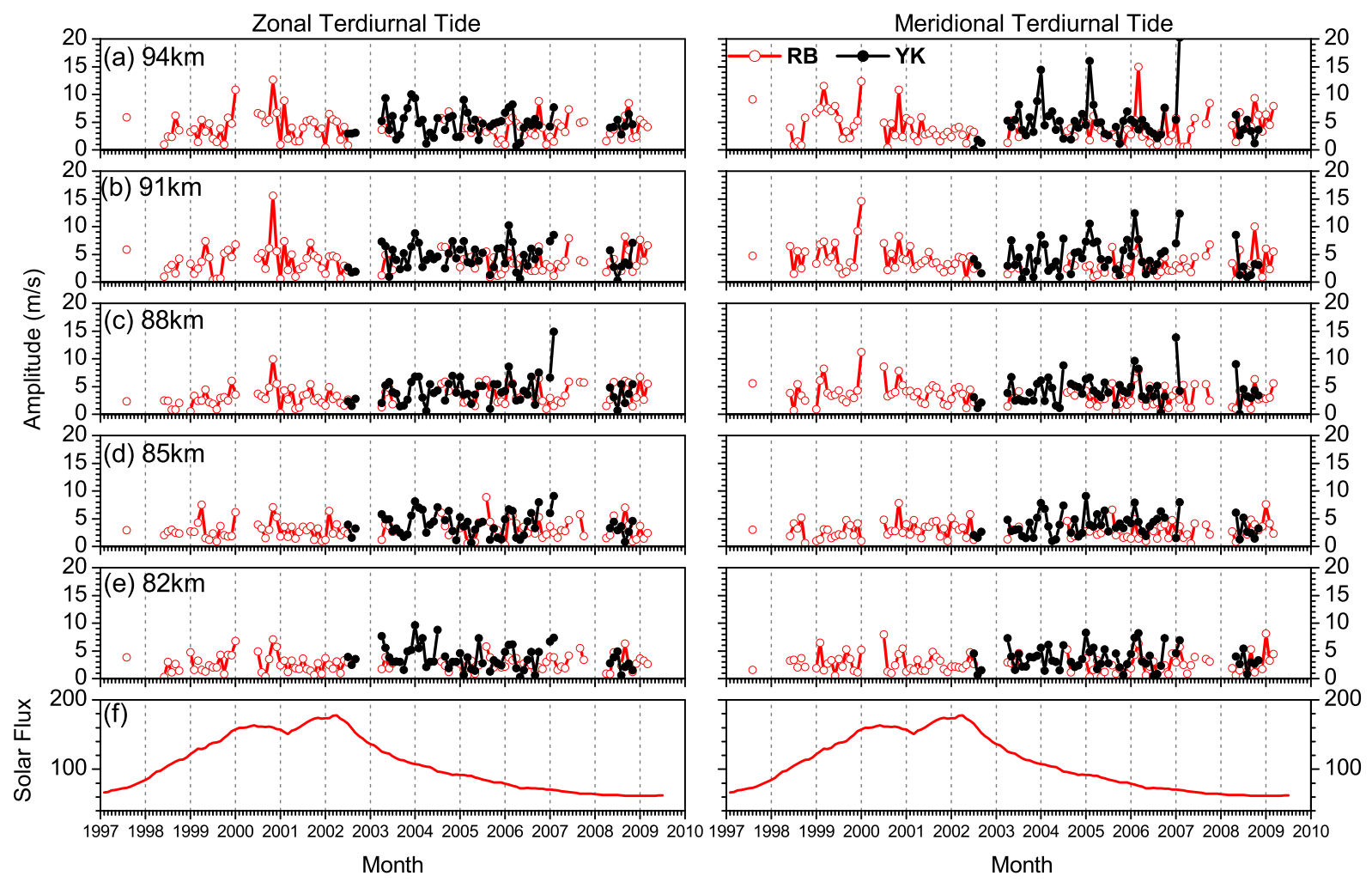

Fig. 7. Similar to Fig. 3, but for terdiurnal tidal amplitudes. 
Figure 5 illustrates clear interannual variability of the diurnal tidal amplitudes. The tidal amplitudes have a maximum during summer and minimum during winter. The zonal tidal amplitudes at RB are stronger than $\mathrm{YK}$, whereas the meridional amplitudes at $\mathrm{YK}$ are stronger than RB. A dominant annual oscillation is evident in both components over the two sites, at least over most heights. At RB, we also found a long period oscillation of around 30 months with significant amplitude in the zonal component below $90 \mathrm{~km}$. No clear long term oscillation is present in the corresponding meridional component. The diurnal phases also show strong annual variation in both zonal and meridional components at RB above $85 \mathrm{~km}$. This annual variation is not evident at YK.

Figure 6 illustrates the interannual variation of the semidiurnal amplitudes over RB and YK. The tidal amplitudes show clear interannual variation. The annual oscillation is not significant over RB in either amplitude or phases, but is significant at YK in amplitude, although not in the phases. The LSP analysis indentified a four month oscillation over both sites in the amplitudes. At higher altitudes a six month oscillation is more dominant than the four month oscillation. The diurnal phases show a semiannual oscillation over both sites RB (82-94 km) and YK (91-94 km) both in zonal and meridional components. Figure 7 illustrates the interannual variation of the terdiurnal tide. The amplitude of the terdiurnal tide is less compared to the diurnal and semidiurnal tidal amplitudes. The annual oscillation amplitude is much less and has less significance both in amplitude and phase over both sites. No dependence of solar activity is evident in the tidal amplitudes for any tidal modes.

We now turn to consideration of vertical wavelengths. It is a tedious process to identify the correct vertical wavelengths, since the phase profiles often have different tidal modes (as discussed earlier). So some screening tests are needed before calculating the vertical wavelength. Based on the screening test, the phase profiles are divided into two categories. Smooth phase profiles which do not have any sudden changes with height are considered as category 1 . The phase profiles which have sudden changes with height are considered as category 2. The pictorial forms of these categories are shown in Fig. 4a-c in Hocking (2001). In addition to these we add the phase profiles with sudden change in category 2 . Only category 1 profiles have been used for vertical wavelength calculation, since the linear fit applied to category 2 can lead to random values. Finally, the percentage of profiles used for vertical wavelength estimation are as follows: $34 \%$ (26\%), 35\% (31\%) and 29\% (10\%) for diurnal, semidiurnal and terdiurnal zonal (meridional) components over RB, respectively, whereas for YK, the values are 66\% (34\%), 60\% $(58 \%)$ and $23 \%(8 \%)$ for diurnal, semidiurnal and terdiurnal zonal (meridional) components, respectively. The percentages which show multiple tidal modes are more often present in the meridional component than in the zonal component. Notice that multiple tidal modes are more common over RB than YK, for the diurnal and terdiurnal tides. The monthly variations of the vertical wavelengths for selected months are shown in Fig. 8. Note that the vertical axis shows the wavelengths depicted with a log scale to better display the short wavelengths.

The number of useful wavelengths determined for some months of the year is reduced due to the randomness of some of the phase profiles. Figure 8 illustrates the large interannual variability of the vertical wavelengths. On average, the vertical wavelengths at RB are larger than at YK. Significant differences have been observed between the vertical wavelengths of the zonal and meridional components at both sites, with a considerable difference at YK in the diurnal tidal component. On average, the RB vertical wavelengths in the diurnal tides are around $100 \mathrm{~km}$ throughout the year in both components, supporting the earlier observations made elsewhere e.g., Avery et al. (1989) and Hocking (2001). At YK, shorter vertical wavelengths occur, with values less than $50 \mathrm{~km}$ during summer and around $70 \mathrm{~km}$ during other months in the zonal component. In the meridional component, the vertical wavelengths are around $100 \mathrm{~km}$ during summer and shorter vertical wavelengths around $80 \mathrm{~km}$ occur during other months. The vertical wavelengths in the semidiurnal tide are larger during equinoxes over both sites in comparison to other months. Both zonal and meridional components show almost the same vertical wavelengths. The vertical wavelengths in the terdiurnal tide are about $25-40 \mathrm{~km}$ and occasionally reach around $70 \mathrm{~km}$ at $\mathrm{RB}$. The observations for terdiurnal tides over YK are comparatively less, so that it is not possible to discriminate the seasonal variation of vertical wavelengths over this site.

\subsection{Tides - comparison with GSWM00 predictions}

In this section, we will discuss the difference between our observations and predictions of the GSWM00 migrating tides. Since the GSWM00 predictions are confined only to diurnal and semidiurnal tides, there is no chance for terdiurnal tidal comparisons. For the comparison of diurnal and semidiurnal tides, we used the predictions over $75^{\circ} \mathrm{N}$ for RB and $63^{\circ} \mathrm{N}$ for YK. The monthly variations of amplitude and phases of the GSWM00 predictions are illustrated in Fig. 9.

The GSWM is the most sophisticated mechanistic model currently available for the 24- and 12-h tides. It is a two-dimensional linearized model that uses solutions to the Navier-Stokes equations to determine wind and temperature perturbations due to tides and planetary waves as a function of height, latitude, wave periodicity, and zonal wave number. This model does not consider any nonlinear interactions between tides and planetary waves. The GSWM has been described in detail by Hagan et al. $(1995,1997,1999)$ and results from the GSWM00 are available at http://www.hao. ucar.edu/modeling/gswm/gswm.html\#ASC24.

The salient features observed from the monthly variations of the predictions are maximum diurnal amplitudes during equinoxes followed by summer, with minimum amplitudes 

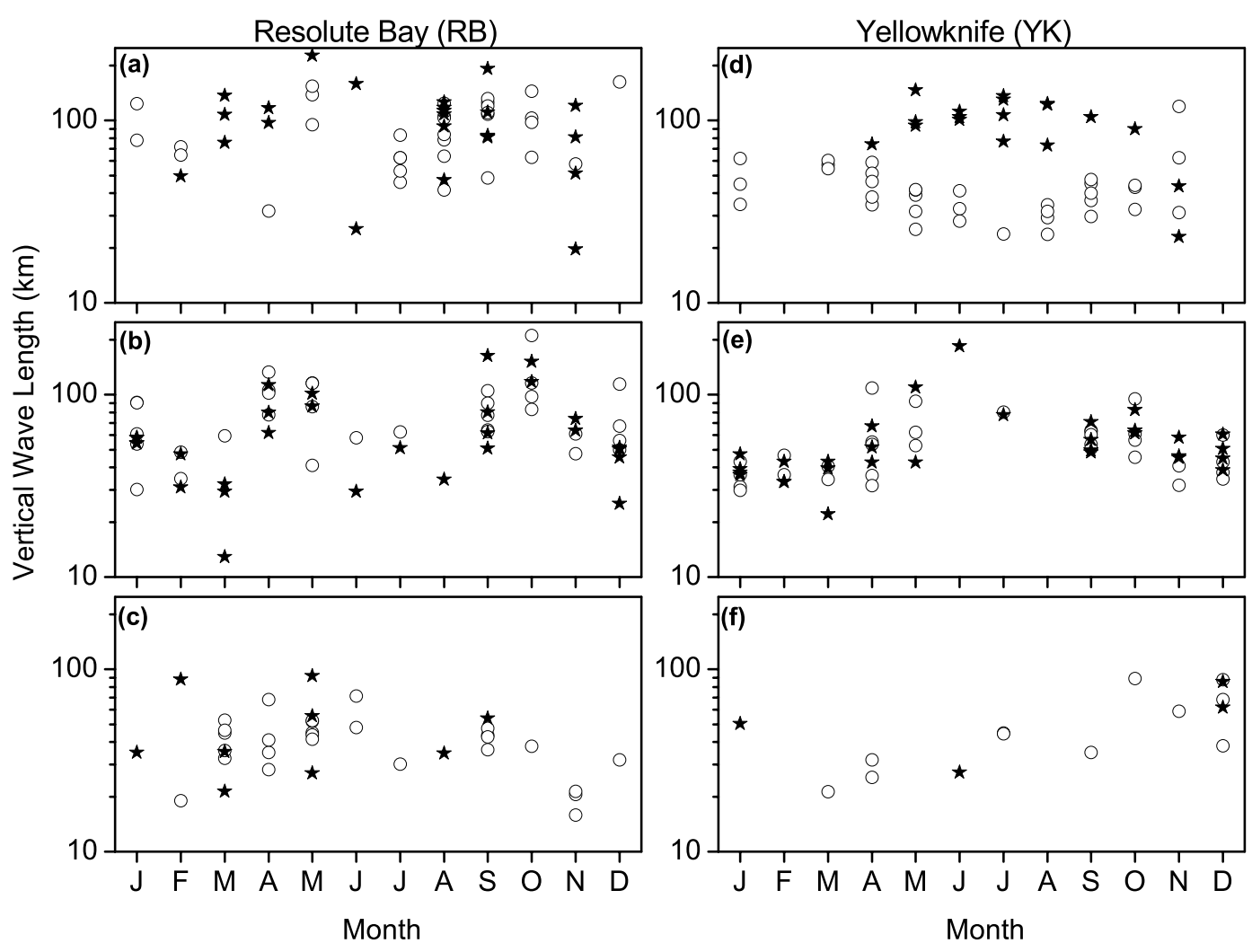

Fig. 8. Monthly variation of vertical wavelengths (a-c) for diurnal, semidiurnal and terdiurnal tides over RB, respectively. Note the vertical wavelengths in zonal (meridional) component are denoted with open circles (filled stars). (d-f) are similar to (a-c) but for YK. Note the vertical axis in logarithmic scale.

during winter; maximum semidiurnal amplitudes during the winter season and fall equinox and minimum during summer season; the diurnal phase profiles show small vertical phase gradients; and the semidiurnal phase profiles show large vertical phase gradients, mainly during equinoxes. Both the predictions over RB and YK are almost similar in nature.

A lot of similarities and differences are identified between the observations and predictions. The model-predicted diurnal amplitudes generally have a good match with the observations, with some exceptions. At RB, above $90 \mathrm{~km}$, especially during the summer months, the model zonal amplitudes underestimate the observations. At YK, the model predictions underestimate the observations above $90 \mathrm{~km}$ during the winter months, whereas below $90 \mathrm{~km}$ the model amplitudes overestimate the observations throughout the year. The model-predicted meridional amplitudes are in good agreement with the observations over RB. The model values underestimate the observations over YK especially for the summer months.

Here we adopt the criteria proposed by Manson et al. (1999) for phase comparisons. The phase is considered as showing good agreement if the difference between model and observed phases is about $6 \mathrm{~h}$ for the diurnal tide and $3 \mathrm{~h}$ for the semidiurnal tide, otherwise it is taken as disagree- ment. We used the climatological monthly mean values with the standard deviation values, which indicate the interannual variability. Finally, we look into whether the modelpredicted phases, with these adopted criteria, are within the climatological limits, to test the agreement of the model predictions. Based on this test, the zonal diurnal phase derived from model predictions are in disagreement with the observations during winter months above $90 \mathrm{~km}$ and during summer months below $90 \mathrm{~km}$. The difference is larger over YK than $\mathrm{RB}$. The meridional diurnal phases are in good agreement with the observations.

In regard to the semidiurnal tidal comparison, the zonal and meridional amplitudes produced by the model are in good agreement with the observations during winter months. During non winter months, the predictions underestimate the observations. During the summer season, the model amplitudes underestimate the amplitudes of the observations by a factor of 3-4 times. The underestimation is larger at $\mathrm{YK}$ in comparison to RB. The model-predicted zonal semidiurnal phases are in disagreement with observations during winter months below $90 \mathrm{~km}$ and during the equinox above $90 \mathrm{~km}$. The meridional semidiurnal phases from predictions are in good agreement with the observations in both the components over both sites. Pancheva et al. (2002), reported that the 

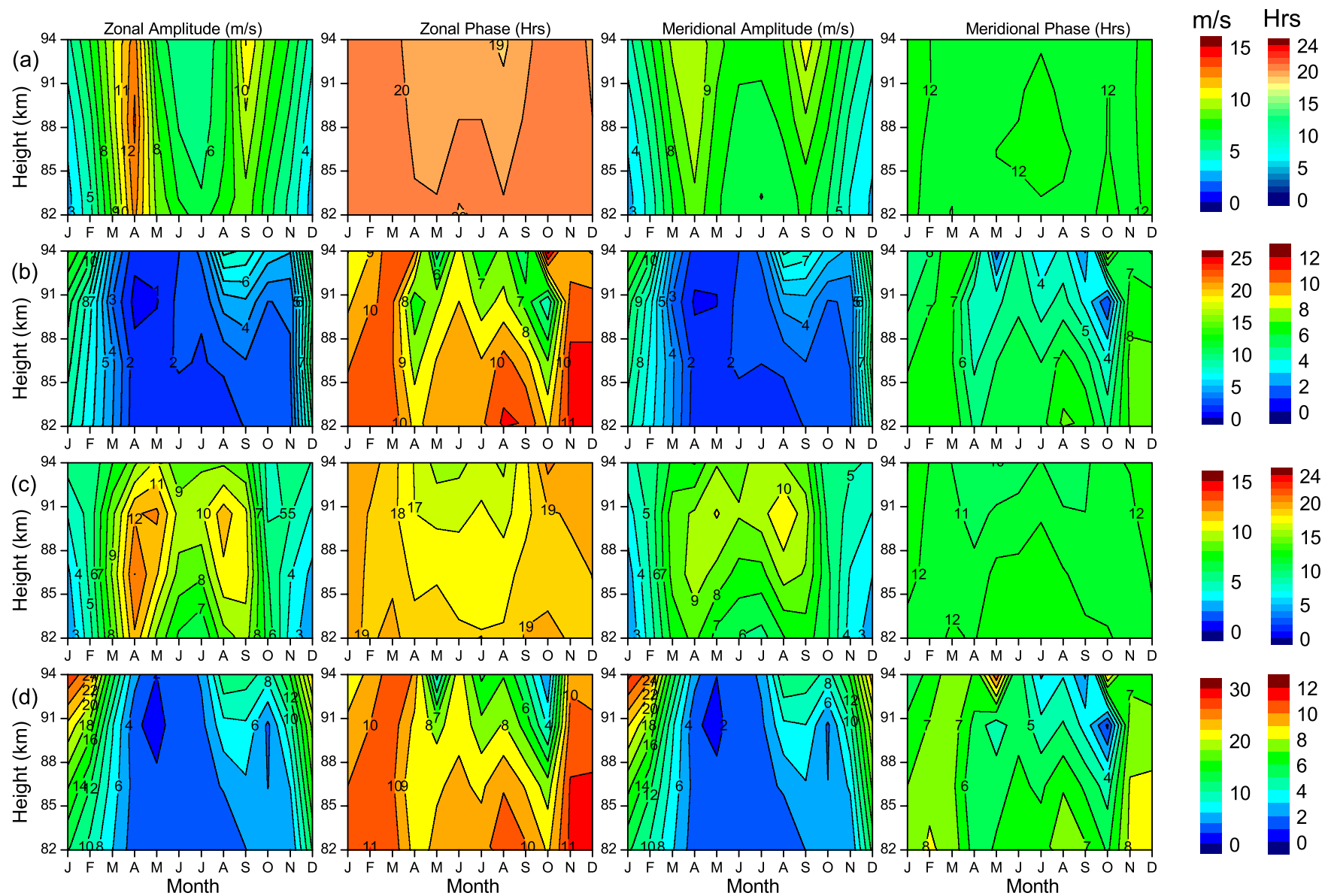

Fig. 9. Monthly variations of GSWM 00 predictions of zonal amplitude, phase, meridional amplitude and phase (a) for diurnal tide over $75^{\circ} \mathrm{N}$ (b) for semidiurnal diurnal tide over $75^{\circ} \mathrm{N}$. (c) and (d) are same as (a) and (b), but over $63^{\circ} \mathrm{N}$. Note that the first color bar is meant for amplitude and the second color bar is meant for phase.

semidiurnal tidal amplitudes of the observations are larger than the GSWM model predictions and the observed phases are good in agreement with model-predicted phases, based on the observations made over different latitudes during the PSMOS campaign of June-August 1999. In the present study, amplitudes and phases are determined by vector averaging, which is a generally accepted procedure (Grieger et al., 2002). Interestingly, however, when we used arithmetic averaging, agreement of the phase with the modelpredictions is much better. The GSWM00 model predictions show rapid phase change at higher heights over both latitudes, which are not evident in the observed phases. The model predictions have sharp phase gradients above $90 \mathrm{~km}$ during equinoxes and the sharp phase gradients are not displayed in observations, which confirm that the model predictions underestimate the vertical wavelengths.

\section{Summary and conclusions}

In this paper, we have presented the long term variations of zonal and meridional winds and tidal amplitudes and phases in the polar MLT region. The study was carried out with nearly 12 years of observations made over Resolute Bay using a VHF radar in meteor mode, and 7 years of observations made over Yellowknife with a SKiYMET meteor radar. The results are of great importance for understanding the mean circulation of the mesosphere. It is well known that gravity wave drag drives a meridional flow which results in upwelling over the summer pole (causing cooling) and downflow at the winter pole (causing adiabatic heating), but the details of the polar circulation are still poorly understood. This paper gives a better picture of the mean motions in the important arctic polar region, especially demonstrating the latitudinal variation in this region, and also the seasonal variability. Features such as the strong asymmetric growth and decay of the summer jet are important (rapid development and slow decay) and are important features that have not yet been included in many models. 
The zonal MLT winds over northern polar latitudes are characterized with summer westward flow at lower and eastward flow at upper heights, and winter eastward flow at all heights. Larger magnitudes occur over YK in comparison to RB. The meridional wind flow is characterized by winter poleward flow and summer equatorward flow, with a jet around $90 \mathrm{~km}$ during peak summer months. The meridional equatorward jet shows clear interannual variability. Both the zonal and meridional winds are dominated by an annual oscillation. During summer months, an increasing trend has been observed in the westward flow and a decreasing trend has been observed in the meridional wind. The zonal winds show some solar cycle dependence, with the zonal winds at RB being more positive during the increasing phase of the solar cycle than during the decreasing phase. The present data set is not sufficient to reveal definitive solar cycle dependence, so we leave this task for future study. An annual oscillation is evident over both sites in the zonal and meridional component.

The climatological mean winds and tides have been compared with different models, specifically the HWM07, GEWM and CIRA 86 for winds and the GSWM00 for the diurnal and semidiurnal tides. We have found both agreement and disagreements between observations and model predictions. Comparisons between observed winds and model winds are summarized as follows:

- The HWM07 model differs considerably with our observations, mainly below $90 \mathrm{~km}$. It needs considerable modifications in both the zonal and meridional wind during winter, if it is to properly represent northern American polar flow.

- Even though the GEWM00 predicts the gross features over northern polar latitudes, it shows some unusual features, such as stronger eastward winds over $75^{\circ} \mathrm{N}$ than $62.5^{\circ} \mathrm{N}$. It also shows a stronger meridional equatorward jet over $75^{\circ} \mathrm{N}$ than at $62.5^{\circ} \mathrm{N}$. This may be due to the smaller amount of data entered into the model as input or it could be because the model uses data from a wide range of longitudes. These drawbacks can be overcome using long term observations as input to the model, since the polar MLT winds have large interannual variability.

- The CIRA 86 model does not well represent the zonal structure over northern polar latitudes, and it has many discrepancies. It does not reproduce the true summer wind flow at higher altitudes (which is mainly an eastward flow), the asymmetry during summer months is missing and the winter flow overestimates the observations.

The tidal amplitudes show clear differences between RB and YK. At RB, diurnal, semidiurnal and terdiurnal tides have similar amplitudes in the zonal and meridional components.
The diurnal amplitudes have a clear seasonal maximum during equinoxes, followed by lesser values in summer and minimum values during winter. The semidiurnal amplitudes are maximum during fall equinox and winter with a minimum during spring equinox. The terdiurnal amplitudes are generally more uniform throughout the year. The existence of multiple tidal modes in all tides is more common at RB than YK. The vertical wavelengths are almost the same in zonal and meridional components over RB. The observed vertical wavelengths over RB are longer than over YK.

At YK, the zonal and meridional components are not the same, at least during some seasons. The meridional diurnal amplitudes are larger than the zonal diurnal amplitudes during summer. Even though the seasonal variations of semidiurnal tide in zonal and meridional components are the same in form, the meridional amplitudes are larger than zonal amplitudes by at least $2-4 \mathrm{~m} \mathrm{~s}^{-1}$. The meridional terdiurnal amplitudes are larger than the zonal amplitudes by at least $1-2 \mathrm{~m} \mathrm{~s}^{-1}$. Vertical wavelengths of diurnal and semidiurnal tides are generally fairly long, with some modest seasonal variation.

The observed amplitudes and vertical wavelengths compare well with the results reported elsewhere. The diurnal amplitudes show significant annual oscillation and also show a 30 month oscillation over RB.

The comparisons made with observed diurnal and semidiurnal tides and GSWM00 predictions gave some conclusions and these are summarized as follows:

- The model-predicted diurnal zonal amplitudes underestimate the observed values above $90 \mathrm{~km}$ during the summer. During winter, the model-predicted diurnal zonal phases above $90 \mathrm{~km}$ are in disagreement with the observed phases. This suggests that the model needs some corrections above $90 \mathrm{~km}$.

- The model-predicted semidiurnal amplitudes underestimate the observed values both in the zonal and meridional components. The model-predicted phases need some more corrections, especially in the zonal component.

Recently Ward et al. (2005) identified, in the extended CMAM, that nonmigrating tides play a significant role in the variability of the dynamics of the mesosphere and lower thermosphere. This may be one of possible reason for the differences between observations and model predictions, since the observed tidal modes are a mix of migrating and nonmigrating tides. Single site studies cannot be used to resolve these different modes.

Acknowledgements. We are thankful to D. P. Drob for providing the HWM07 model winds and Yuri Portnyagin for providing GEWM model winds. The research was funded by the Natural Sciences and Engineering Research Council of Canada. Support from the staff at NARWHAL in Resolute Bay and George Jensen in Yellowknife is also appreciated. 
Topical Editor C. Jacobi thanks two anonymous referees for their help in evaluating this paper.

\section{References}

Avery, S. K., Vincent, R. A., Phillips, A., Manson, A. H., and Fraser, G. J.: High-latitude tidal behaviour in the mesosphere and lower thermosphere, J. Atmos. Terr. Phys., 51, 595-608, doi:10.1016/0021-9169(89)90057-3, 1989.

Burrage, M. D., Hagan, M. E., Skinner, W. R., Wu, D. L., and Hays, P. B.: Long-term variability in the solar diurnal tide observed by HRDI and simulated by the GSWM, Geophys. Res. Lett., 22, 2641-2644, doi:10.1029/95GL02635, 1995.

Day, K. A. and Mitchell, N. J.: The 5-day wave in the Arctic and Antarctic mesosphere and lower thermosphere, J. Geophys. Res., 115, D01109, doi:10.1029/2009JD012545, 2010.

Drob, D. P., Emmert, J. T., Crowely, G., Picone, J. M., et al.: An empirical model of the Earth's horizontal wind fields: HWM07, J. Geophys. Res., 113, A12304, doi:10.1029/2008JA013668, 2008.

Grieger, N., Volodin, E. M., Schmitz, G., Hoffmann, P.,Manson, A. H., Fritts, D. C., Igarashi, K., and Singer, W.: General circulation model results on migrating and nonmigrating tides in the mesosphere and lower thermosphere. Part I: comparison with observations, J. Atmos. and Sol. Terr. Phys., 64, 897-911, doi:10.1016/S1364-6826(02)00045-7, 2002.

Hagan, M. E., Forbes, J. M., and Vial, F.: On modelling migrating solar tides, Geophys. Res. Lett., 22, 893-896, doi:10.1029/95GL00783, 1995.

Hagan, M. E., Chang, J. L., and Avery, S. K.: GSWM estimates of non-migrating tidal effects, J. Geophys. Res., 102, 16439-16452, doi:10.1029/97JD01269, 1997.

Hagan, M. E., Burrage, D. M., Forbes, J. M., Hackney, J., Randel, W. J., and Zhang, X.: GSWM-98: Results for migrating solar tides, J. Geophys. Res., 104, 6813-6827, doi:10.1029/1998JA900125 1999.

Hall, C. M., Aso, T., Manson, A. H., Meek, C. E., Nozawa, S., and Tsutsumi, M.: High-latitude mesospheric mean winds: A comparison between Troms $\varnothing\left(69^{\circ} \mathrm{N}\right)$ and Svalbard $\left(78^{\circ} \mathrm{N}\right)$, J. Geophys. Res., 108(D19), 4598, doi:10.1029/2003JD003509, 2003.

Hocking, W. K., and Thayaparan, T.: Simultaneous and co-located observation of winds and tides by MF and Meteor radars over London, Canada, (43 N, 81 W) during 1994-1996, Radio Sci., 32, 833-865, doi:10.1029/96RS03467, 1997.

Hocking, W. K.: Middle atmosphere dynamical studies at Resolute Bay over a full year: Mean winds, tides and special oscillations, Radio Sci., 36, 1795-1822, doi:10.1029/2000RS001003, 2001.

Hocking, W. K., Fuller, B., and Vandepeer, B.: Real-time determination of meteor-related parameters utilizing modem digital technology, J. Atmos. Sol. Terr. Phys., 63, 155-169, doi:10.1016/S1364-6826(00)00138-3, 2001.

Jacobi, Ch., Arras, C., Kurschner, D., Singer, W., Hoffmann, P., and Keuer, D.: Comparison of mesopause region meteor radar winds, medium frequency radar winds and low frequency drifts over Germany, Adv. Space Res., 43, 247-252, doi:10.1016/j.asr.2008.05.009, 2009.

Kishore Kumar, G., Ratnam, M. V., Patra, A. K., Rao, V. V. M. J., Rao, S. V. B., Kumar, K. K., Gurubaran, S., Ramkumar, G., and Rao, D. N.: Low-latitude mesospheric mean winds observed by Gadanki mesosphere-stratosphere-troposphere (MST) radar and comparison with rocket, High Resolution Doppler Imager (HRDI), and MF radar measurements and HWM93, J. Geophys. Res., 113, D19117, doi:10.1029/2008JD009862, 2008.

Kishore, P., Namboothiri, S. P., Igarashi, K., Murayama, Y., and Watkins, B. J.: MF radar observations of mean winds and tides over Poker Flat, Alaska (65.1 $\left.{ }^{\circ} \mathrm{N}, 147.5^{\circ} \mathrm{W}\right)$, Ann. Geophys., 20, 679-690, doi:10.5194/angeo-20-679-2002, 2002.

Lomb, N. R.: Least-squares frequency analysis of unequally spaced data, Astrophys. Space Sci., 39, 447-462, doi:10.1007/BF00648343, 1976.

Manning, L. A., Villard, O. G., and Peterson, A. M.: Meteoric echo study of upper atmosphere winds, Proceedings of I.R.E., 38, 877-883, doi:10.1109/JRPROC.1950.234124, 1950.

Manson, A. H., Meek, C. E., Avery, S. K., and Tetenbaum, D.: Comparison of mean wind and tidal fields at Saskatoon $\left(52^{\circ} \mathrm{N}\right.$, $\left.107^{\circ} \mathrm{W}\right)$ and Poker Flat $\left(65^{\circ} \mathrm{N}, 147^{\circ} \mathrm{W}\right)$ during $1983 / 1984$, Phys. Scr., 37, 169-177, doi:10.1088/0031-8949/37/1/027, 1988.

Manson, A. H. and Meek, C. E.: Climatologies of mean winds and tides observed by medium frequency radars at Troms $\varnothing\left(70^{\circ} \mathrm{N}\right)$ and Saskatoon $\left(52^{\circ} \mathrm{N}\right)$ during 1987-1989, Can. J. Phys., 69, 966-975, doi:10.1139/p91-152, 1991.

Manson, A. H., Meek, C. E., Brekke, A., and Moen, J.: Mesosphere and lower thermosphere $(80-120 \mathrm{~km})$ winds and tides from near Troms $\varnothing\left(70^{\circ} \mathrm{N}, 19^{\circ} \mathrm{E}\right)$ : Comparisons between radars (MF, EISCAT, VHF) and rockets, J. Atmos. Terr. Phys., 54, 927-950, doi:10.1016/0021-9169(92)90059-T, 1992.

Manson, A., Meek, C., Hagan, M., Hall, C., et al.: Seasonal variations of the semi-diurnal and diurnal tides in the MLT: Multi-year MF radar observations from 2 to $70^{\circ} \mathrm{N}$, and the GSWM tidal model, J. Atmos. Sol. Terr. Phys., 61, 809-828, doi:10.1016/S1364-6826(99)00045-0, 1999.

Manson, A. H., Meek, C. E., Chshyolkova, T., Xu, X., Aso, T., Drummond, J. R., Hall, C. M., Hocking, W. K., Jacobi, Ch., Tsutsumi, M., and Ward, W. E.: Arctic tidal characteristics at Eureka $\left(80^{\circ} \mathrm{N}, 86^{\circ} \mathrm{W}\right)$ and Svalbard $\left(78^{\circ} \mathrm{N}, 16^{\circ} \mathrm{E}\right)$ for $2006 / 07$ : seasonal and longitudinal variations, migrating and non-migrating tides, Ann. Geophys., 27, 1153-1173, doi:10.5194/angeo-271153-2009, 2009.

Mitchell, N. J., Pancheva, D., Middleton, H. R., and Hagan, M. E.: Mean winds and tides in the Arctic mesosphere and lower thermosphere, J. Geophys. Res., 107(A1), 1004, doi:10.1029/2001JA900127, 2002.

Miyahara, S. and Forbes, J. M.: Interactions between gravity waves and the diurnal tide in the mesosphere and lower thermosphere, J. Meteorol. Soc. Jpn., 69, 523-531, 1991.

Nakamura, T., Tsuda, T., and Fukao, S.: Mean winds at $60-90 \mathrm{~km}$ observed with the MU radar $\left(35^{\circ} \mathrm{N}\right)$, J. Atmos. Terr. Phys., 58, 655-660, doi:10.1016/0021-9169(95)00064-X, 1996.

Oberheide, J., Wu, Q., Killeen, T. L., Hagan, M. E., and Roble, R. G.: Diurnal nonmigrating tides from TIMED Doppler Interferometer wind data: Monthly climatologies and seasonal variations, J. Geophys. Res., 111, A10S03, doi:10.1029/2005JA011491, 2006.

Pancheva, D., Mitchell, N. J., Hagan, M. E., Manson, A. H., et al.: Global-scale tidal structure in the mesosphere/lower thermosphere region during the PSMOS campaign of June-August 1999 and comparison with the GSWM, J. Atmos. Sol. Terr. Phys., 64, 1011-1035, doi:10.1016/S1364-6826(02)00054-8, 2002.

Portnyagin, Yu., Solovjova, T., Merzly, E., Frobes, J., et al.: Meso- 
sphere/lower thermosphere prevailing wind model, Adv. Space. Res., 34(8), 1755-1762, doi:10.1016/j.asr.2003.04.058, 2004.

Robertson, D. S., Liddy, D. T., and Elford, W. G.: Measurements of winds in the upper atmosphere by means of drifting meteor trails I, J. Atmos. Terr. Phys., 4, 255-266, doi:10.1016/00219169(53)90059-2, 1953.

Scargle, J. D.: Studies in astronomical time series analysis. II Statistical aspects of spectral analysis of unevenly spaced data, Astrophys. J., Part 1, 263, 835-853, doi:10.1086/160554, 1982.

Smith, A. K.: Structure of the terdiurnal tide at $95 \mathrm{~km}$, Geophys. Res. Lett., 27, 177-180, doi:10.1029/1999GL010843, 2000.

Teitelbaum, H., Vial, F., Manson, A. H., Giraldez, R., and Massebeuf, M.: Non-linear interaction between the diurnal and semidiurnal tides: Terdiurnal and diurnal secondary waves, J. Atmos. Terr. Phys., 51, 627-634, doi:10.1016/0021-9169(89)90061-5, 1989.
Thayaparan, T.: The terdiurnal tide in the mesosphere and lower thermosphère over London, Canada $\left(43^{\circ} \mathrm{N}, 81^{\circ} \mathrm{W}\right)$, J. Geophys. Res., 02(D18), 21695-21708, doi:10.1029/97JD01839, 1997.

Tsuda, T., Aso, T., and Kato, S.: Seasonal variation of solar atmospheric tides at meteor heights, J. Geomagn. Geoelectr., 35, 65-86, 1983.

Younger, P. T., Pancheva, D., Middleton, H. R., and Mitchell, N. J.: The 8-hour tide in the Arctic mesosphere and lower thermosphere, J. Geophys. Res., 107(A12), 1420, doi:10.1029/2001JA005086, 2002.

Ward, W. E., Fomichev, V. I., and Beagley, S.: Nonmigrating tides in equinox temperature fields from the Extended Canadian Middle Atmosphere Model (CMAM), Geophys. Res. Lett., 32, L03803, doi:10.1029/2004GL021466, 2005. 